Federal Reserve Bank of Dallas

Globalization and Monetary Policy Institute

Working Paper No. 66

http://www.dallasfed.org/assets/documents/institute/wpapers/2010/0066.pdf

\title{
The Adverse Feedback Loop and the Effects of Risk in both the Real and Financial Sectors*
}

\author{
Scott Davis \\ Federal Reserve Bank of Dallas
}

November 2010

\begin{abstract}
Recessions that are accompanied by financial crises tend to be more severe and are followed by slower recoveries than ordinary recessions. This paper introduces a new Keynesian model with financial frictions on both the demand and supply side of the credit markets that can explain this empirical finding. Following a shock that leads to a decline in economic activity, an adverse feedback loop arises where falling profits and asset values lead to increased defaults in the real sector, and these increased defaults lead to increased loan losses in the banking sector. Following this increase in loan losses, financial frictions in the banking sector imply that the banking sector itself may face difficulty obtaining funds. This disruption in the intermediation process leads to a further decline in output and asset prices in the real sector. In simulations of the model it is found that this feedback loop operating through the balance sheets of financial intermediaries can lead to as much as a $20 \%$ increase in business cycle volatility, and impulse response analysis shows that in the presence of financial frictions the path back to the steady state after a shock is much slower.
\end{abstract}

JEL codes: E32, E44, F40, G01

\footnotetext{
*Scott Davis, Federal Reserve Bank of Dallas, 2200 N. Pearl Street, Dallas, TX 75201. 214-922-5124. Scott.davis@dal.frb.org. I would like to thank Mario Crucini, Kevin Huang, Andrew Hughes Hallett, Enrique Martinez-Gracia, Elias Papaioannou, and Michael Plante for many helpful comments and suggestions. I would also like to thank the participants at the 2010 ASSA meetings, the 2010 Midwest Macro Meetings, and the 6th Annual Dynare Conference. The views in this paper are those of the author and do not necessarily reflect the views of the Federal Reserve Bank of Dallas or the Federal Reserve System.
} 


\section{Introduction}

Ensconced in the comfort of the Great Moderation, macroeconomists largely ignored the process of financial intermediation and felt comfortable to treat finance simply as a "veil", until the Great Panic and Great Contraction of 2007-2008 dramatically changed the way we view the interplay between finance and the macroeconomy. ${ }^{1}$

In the wake of the financial crisis, a number of authors have looked to the history of financial crises to find evidence of their macroeconomic effects. Papers like Reinhart and Rogoff (2008 and 2009), Cecchetti, Kohler, and Upper (2009), The IMF (2009a and 2009b), Bordo and Haubrich (2010), Claessens et al. (2010) and Reinhart and Reinhart (2010) all find that an economic downturn accompanied by a financial crisis tends to be more severe and more protracted than an ordinary recession.

This paper presents a simple, highly tractable model to explain the severity of a recession that is accompanied by a financial crisis. In the model, a shock (either real or nominal) leads to a fall in economic activity, which causes a fall in asset prices and increased defaults in the real sector of the economy. These increased defaults in the real sector lead to loan losses in the financial sector. This deterioration in both real and financial sector balance sheets leads to a reduction in the supply of credit to both sectors, causing an even greater fall in economic activity and a further fall in asset prices.

This amplification mechanism, also called the adverse feedback loop, may explain a large part of the Great Contraction following the Great Panic of $2008 .^{2}$ However it is absent from most macroeconomic models, for both Real Business Cycle models based on classical assumptions and models based on Keynesian assumptions assume perfect information and thus accept irrelevance of financial conditions implied by the Modigliani and Miller (1958) theorem.

Some papers move beyond the conditions of the Modigliani-Miller theorem and incorporate

\footnotetext{
${ }^{1}$ In his 2009 Schumpeter Lecture to the Congress of the European Economic Association, Charles Bean predicts that in all probability, the events of 2007-2008 will join the Great Depression of the 1930's and the Great Inflation of the 1970's as "discipline-defining events" (Bean 2009)

${ }^{2}$ In congressional testimony, Federal Reserve Chairman Ben Bernanke referred to "the destructive power of the so-called adverse feedback loop, in which weakening economic and financial conditions become mutually reinforcing." (Bernanke 2009)
} 
financial frictions into a general equilibrium model. ${ }^{3}$ In the first example of financial frictions in a general equilibrium, Bernanke and Gertler (1989) rely upon agency costs and asymmetric information to produce the "financial accelerator". In this model, borrowing costs are inversely related to a borrower's net worth. If this net worth is procyclical, then borrowing costs should fall in booms and rise in recessions, amplifying both. Carlstrom and Fuerst (1997) apply the agency cost problem to a quantitative real business cycle model, and find that the financial accelerator mechanism can help explain the hump-shaped dynamic of output in response to a technology shock. Furthermore, Bernanke et al. (1999) apply the financial accelerator in a model with sticky prices to show how financial frictions can affect the economy's response to monetary shocks. In a related strand of literature, Kiyotaki and Moore (1997) show how credit market frictions, in the form of collateral requirements, introduce an important mechanism for the propagation of technology shocks. In addition, Iacoviello (2005) and Christiano et al. (2008) construct models with a financial accelerator and nominal debt contracts to highlight the debt-deflation channel from Fisher (1933). They show how the non-indexation of debt combined with financial frictions can serve to amplify the effects of demand shocks that produce a positive co-movement between output and inflation and dampen the effect of supply shocks, which produce a negative co-movement.

In these papers, which form the "core" of the financial accelerator literature, there is not a specific role for financial intermediaries. However, to model the macroeconomic effects of a crisis in the financial sector it is necessary to incorporate financial frictions in the intermediary sector itself. In addition, many empirical studies have produced results that seem to contrast with the irrelevance of financial conditions in the intermediary sector. ${ }^{4}$

Abstracting from the conditions of the Modigliani and Miller theorem, Holstrom and Tirole (1997), Stein (1998), Chen (2001) and von Peter (2009) present models where the bank net worth matters for the quantity of intermediation.

\footnotetext{
${ }^{3}$ See Gertler (1988) for a survey of how the literature of financial frictions arose out of the literature incorporating imperfect information.

${ }^{4}$ The relevance of financial conditions in the intermediary sector is a central part of the bank-lending channel of monetary policy transmission Bernanke and Gertler 1995.

Bernanke (1983), Bernanke and Lown (1991), Peek and Rosengren (2000), Lown and Morgan (2006), and Gilchrist et al. (2009) attempt to isolate exogenous frictions in the credit markets and find robust evidence that disturbances arising from within the financial intermediation process can have real effects.

Kashyap and Stein (1995 and 2000) find that the impact of monetary policy on a particular bank's lending behavior depends on its balance sheet strength, and they interpret this as evidence that a bank's funding cost depends on its financial conditions. In addition Hubbard et al. (2002) shows that there is a relationship between a borrower's cost of funds and the health of his bank's balance sheet.
} 
Motivated by the recent crisis and the central role of the increase in interbank lending spreads (see Taylor and Williams 2009), a number of recent papers incorporate financial frictions within the intermediary sector in a quantitative business cycle model (see e.g. Aikman and Paustain 2006, Gertler and Karadi 2009, Gertler and Kiyotaki 2010, Gilchrist et al. 2009, Curdia and Woodford 2009, Hirakata, Sudo, and Ueda 2009 and 2010, Dib 2010, and Meh and Moran 2010 and see Woodford (2010) for an excellent discription of the ways that the recent crisis has affected the course of macroeconomic and business cycle research).

Adrian and Shin (2008) and Adrian, Monench, and Shin (2010a and 2010b) detail the effects of endogenous changes in the size of financial sector balance sheets as banks and other financial intermediaries change the ratio of debt to equity on their balance sheet in response to changes in the cost of debt. In addition, Van Den Heuvel (2009) writes specifically of the "bank capital channel" of monetary policy transmission (as opposed to the "bank lending channel") whereby monetary policy leads to changes in a bank's net worth and in the presence of financial frictions in the banking sector, this change in net worth affects the supply of lending from the intermediary sector.

Inspired by this research into the macroeconomic effects of changes in a bank's net worth, this paper presents a model with financial frictions in both the real and financial sectors, which are linked through the balance sheets of financial intermediaries.

In the model, a shock that leads to a decline in output and asset prices leads to a fall in net worth in the real sector of the economy. This, combined with financial frictions in the real sector, will lead to a feedback look where worsening balance sheets lead to increased credit risk, and thus lenders curtail lending or charge higher rates, leading to a further decline in economic activity and asset prices.

But when frictions are also introduced within the financial sector, the power of this feedback loop is significantly enhanced. In the model, financial intermediaries (banks) make loans to the real sector. Increased credit risk and increased defaults in the real sector lead to a worsening of balance sheets in the financial sector. As in Stein (1998) there is uncertainty about the health of a particular bank's balance sheet. This uncertainty forms the basis of financial frictions in the financial sector.

Thus in addition to the first feedback loop that results solely from frictions in the real sector, 
a second feedback loop arises from the combination of financial frictions in both the real and financial sectors. The initial shock leads to increased credit risk and increased defaults in the real sector, which leads to a worsening of balance sheets in the banking sector. As bank balance sheets deteriorate, creditors become reluctant to lend to banks and interbank rates increase. When banks receive less funding, or are forced to pay a higher rate, they pass this on to their borrowers, leading to a curtailment of lending to the real sector and thus a further decline in output and asset prices.

Thus two types of financial frictions give rise to two types of feedback loops. Both of these feedback loops lead to the amplification of shocks, which increases the severity of the economic downturn following the initial shock and slows the recovery. However the model in this paper will show how the second feedback loop, that has to do with the health of a bank's balance sheet, is stronger than the first.

This is due to two factors that are particular to the financial sector. First, financial frictions in the real sector alone primarily affect access to longer term physical capital financing. But the financial sector also plays an important role in providing short term working capital financing to firms. As demonstrated in the crisis of 2008, when there are problems in the financial sector, firms have trouble fulfilling their working capital needs as well. The model in this paper shows how a significant portion of the extra amplification due to financial frictions in the intermediary sector is due to the effect of these frictions on the market for short term financing.

The second factor that makes the feedback loop due to frictions in the intermediary sector so potent is the fact that banks have relatively small capital cushions. Firms in the non-financial sector maintain much higher capital-asset ratios than firms in the financial sector. This implies that they are more cushioned against a fall in the value of their assets. By examining simulations of the model under alternative scenarios related to the financial sector's capital-asset ratio, this paper shows how the strength of the feedback loop arising because of frictions in the intermediary sector is directly proportional to financial sector leverage.

This paper will proceed as follows. Section 2 presents the model used to explain how recessions accompanied by financial crises tend to be longer and more severe than ordinary recessions. The model is a multi-country new Keynesian model, with financial frictions introduced in both the real and financial sectors that enable the model to move away from the irrelevance of balance sheets implied by the Modigliani and Miller theorem. Then the calibration of the model is discussed 
in section 3. The results from simulations of the model are presented in section 4 . The results are presented in three parts. First, impulse responses show how financial frictions can lead to greater business cycle volatility and persistence following both productivity and monetary policy shocks. Second, we compute the volatility and co-movement of GDP its components and show how the second moments of the business cycle change between versions of the model where we "turn-on" various financial frictions. Thirdly, we consider a new type of shock, tied to frictions in the intermediary sector, that can be though of as an exogenous shock to financial risk. Finally, section 5 concludes and offers some suggestions for further research.

\section{Model}

In the model there are five types of agents: firms, entrepreneurs, capital builders, banks, and households. There is also a central bank that sets the risk free nominal rate of interest.

Firms use capital and labor inputs to produce tradeable output that is used for consumption and investment. Each firm produces a differentiated good and sets prices according to a Calvo (1983) style price setting framework, thus giving rise to nominal price rigidity.

Entrepreneurs own physical capital and rent it to firms. This physical capital is financed partially through debt and partially through equity. In every period, an individual entrepreneur faces an idiosyncratic shock to the value of their physical capital assets. While these shocks have no direct aggregate effects, they introduce heterogeneity among entrepreneurs. The shock is uninsurable, and a fraction of entrepreneurs may experience an abnormally large shock to the value of their physical capital stock and be pushed into bankruptcy, while most will not. The uncertainty over which entrepreneurs will be pushed into bankruptcy and which will not is a type of financial friction in the real sector. The ratio of debt to equity on an entrepreneur's balance sheet determines their ability to withstand an abnormally large shock to the value of their capital stock. Creditors use the entrepreneur's debt-equity ratio to determine the riskiness of lending to the entrepreneurial sector, giving rise to a default risk interest premium that depends on the debt-equity ratio. ${ }^{5}$

Capital builders purchase final goods from firms for physical capital investment. There are diminishing marginal returns to physical capital investment. In periods when investment is high,

\footnotetext{
${ }^{5}$ The fact that this idiosyncratic shock is uninsurable provides the necessary violation of the complete markets assumption necessary to overcome the implications of the Miller and Modigliani theorem.
} 
the marginal return of that investment in producing new physical capital is low, and vice versa. This gives rise to a procyclical relative value of physical capital.

Banks channel savings from households to firms in the form of working capital loans and to entrepreneurs in the form of physical capital loans. A bank finances its asset portfolio partially through equity and partially through debt, which is made up of deposits from domestic and foreign households.

Due to bankruptcies in the real sector, a portion of a bank's portfolio of physical capital loans will go into default in any given period. While these loan losses are not great enough to push the entire banking sector into insolvency, there is heterogeneity among banks with regards to their exposure to the set of non-performing loans. A few banks may be over-exposed to the set of bad loans, and they themselves may be pushed into insolvency. The uncertainty about which banks are over-exposed to the set of non-performing loans and which are not is a type of financial friction in the banking sector. The ratio of debt to equity on a bank's balance sheet determines their ability to absorb loan losses, so the debt-equity ratio determines the ex-ante riskiness of a particular bank. This gives rise to an environment where the spread between interbank lending rates and the risk free rate is increasing in the leverage ratio of the banking sector.

Households supply labor to firms and consume final output. Furthermore they supply a differentiated type of labor and set wages according to a Calvo-style wage setting process, giving rise to nominal wage rigidity.

Finally, the central bank tries to stabilize output and prices by controlling the risk free nominal rate of interest.

The remainder of this section presents the actual details of the model. The model is a twocountry, two-good model. In section 4 we will examine the model in the case of a closed economy, two large open economies, and a small open economy. In the model's notation, the relative size of the home country is $n$ and the relative size of the foreign country is $1-n$. The small open economy is modeled as the home country where $n \rightarrow 0$. The closed economy is the foreign country under the same parameterization (and thus $1-n \rightarrow 1$ ). In the case of two large economies, $n=\frac{1}{2}$.

In what follows, all variables are written in per capita terms and foreign variables are distinguished by an asterisk $(*)$. Relative country size is the only source of cross-country heterogeneity in the model, so foreign equations have been omitted for brevity except where absolutely necessary. 


\subsection{Firms}

In the home country, intermediate goods producing firms, indexed $i \in[0 n]$, combine capital and labor, $k_{t}(i)$ and $h_{t}(i)$ to produce a unique intermediate good $Y_{t}(i)$. The firm's production function is:

$$
Y_{t}(i)=A_{t} h_{t}(i)^{1-\alpha} k_{t}(i)^{\alpha}-\phi
$$

where $A_{t}$ is an exogenous country specific stochastic TFP parameter that is common to all firms and $\phi$ is a fixed cost parameter that is calibrated to ensure that firms earn zero profit in the steady state.

The output from firm $i$ can be sold to the domestic market or sold as imports in the foreign market:

$$
Y_{t}(i)=y_{t}^{d}(i)+y_{t}^{m *}(i)
$$

where $y_{t}^{d}(i)$ is output from firm $i$ that is sold domestically and $y_{t}^{m *}(i)$ is the output that is imported into the foreign country.

Intermediate goods from domestic and foreign firms are then combined into one aggregate final good. As in Chari, Kehoe, and McGrattan (2002), domestically supplied and imported intermediate goods are aggregated by the following:

$$
y_{t}=\left[(\gamma)^{\frac{1}{\rho}}\left[\left(\int_{0}^{n} y_{t}^{d}(i)^{\frac{\sigma-1}{\sigma}} d i\right)^{\frac{\sigma}{\sigma-1}}\right]^{\frac{\rho-1}{\rho}}+\left(\gamma^{f}\right)^{\frac{1}{\rho}}\left[\left(\int_{n}^{1} y_{t}^{m}(i)^{\frac{\sigma-1}{\sigma}} d i\right)^{\frac{\sigma}{\sigma-1}}\right]^{\frac{\rho-1}{\rho}}\right]^{\frac{\rho}{\rho-1}}
$$

where $\sigma$ is the elasticity of substitution between domestic varieties and $\rho$ is the elasticity of substitution between home and foreign varieties.

From this aggregator function the demand in the home country for the intermediate good from domestic firm $i$, where $i \in[0 n]$, as a function of aggregate demand is:

$$
y_{t}^{d}(i)=\gamma(n)^{\frac{1-\rho}{1-\sigma}-1}\left(\frac{P_{t}^{d}(i)}{P_{t}^{d}}\right)^{-\sigma}\left(\frac{P_{t}^{d}}{P_{t}}\right)^{-\rho} y_{t}
$$

Similarly, the demand in the home country for the intermediate good from foreign firm $i$, where 
$i \in(n 1]$, as a function of aggregate demand is:

$$
y_{t}^{m}(i)=\gamma^{f}(1-n)^{\frac{1-\rho}{1-\sigma}-1}\left(\frac{P_{t}^{m}(i)}{P_{t}^{m}}\right)^{-\sigma}\left(\frac{P_{t}^{m}}{P_{t}}\right)^{-\rho} y_{t}
$$

where $P_{t}^{d}(i)$ is the price in the domestic market for the intermediate good from firm $i, P_{t}^{d}=$ $\left(\frac{1}{n} \int_{0}^{n}\left(P_{t}^{d}(i)\right)^{1-\sigma} d i\right)^{\frac{1}{1-\sigma}}$ is a price index of domestically produced intermediate goods, $P_{t}^{m}=$ $\left(\frac{1}{1-n} \int_{n}^{1}\left(P_{t}^{m}(i)\right)^{1-\sigma} d i\right)^{\frac{1}{1-\sigma}}$ is a price index of imported intermediate goods, and the aggregate price level is given by $P_{t}=\left[\gamma(n)^{\frac{1-\rho}{1-\sigma}}\left(P_{t}^{d}\right)^{1-\rho}+\gamma^{f}(1-n)^{\frac{1-\rho}{1-\sigma}}\left(P_{t}^{m}\right)^{1-\rho}\right]^{\frac{1}{1-\rho}}$.

Firm $i$ can discriminate when setting prices for the domestic or foreign market. Thus they can set separate prices for the domestic and export markets. In period $t$, the firm will be able to change its price in the domestic market with probability $1-\xi_{p}$. If the firm cannot change prices then they are reset automatically according to $P_{t}^{d}(i)=\pi_{t-1} P_{t-1}^{d}(i)$, where $\pi_{t-1}=\frac{P_{t-1}}{P_{t-2}}$.

Thus if allowed to change their domestic price in period $t$, the firm will set a price to maximize:

$$
\max _{P_{t}^{d}(i)} E_{t} \sum_{\tau=0}^{\infty} \beta^{\tau}\left(\xi_{p}\right)^{\tau} \lambda_{t+\tau}\left\{\Pi_{t, t+\tau} P_{t}^{d}(i) y_{t+\tau}^{d}(i)-M C_{t+\tau} y_{t+\tau}^{d}(i)\right\}
$$

where $\lambda_{t}$ is the marginal utility of income in period $t$. As discussed in this paper's technical appendix, the firm that is able to change its domestic price in period $t$ will set its price to:

$$
P_{t}^{d}(i)=\frac{\sigma}{\sigma-1} \frac{E_{t} \sum_{\tau=0}^{\infty} \beta^{\tau}\left(\xi_{p}\right)^{\tau} \lambda_{t+\tau} M C_{t+\tau}\left(\frac{\Pi_{t, t+\tau}}{P_{t+\tau}^{d}}\right)^{-\sigma}\left(\frac{P_{t+\tau}^{d}}{P_{t+\tau}}\right)^{-\rho} y_{t+\tau}}{E_{t} \sum_{\tau=0}^{\infty} \beta^{\tau}\left(\xi_{p}\right)^{\tau} \lambda_{t+\tau} \Pi_{t, t+\tau}\left(\frac{\Pi_{t, t+\tau}}{P_{t+\tau}^{d}}\right)^{-\sigma}\left(\frac{P_{t+\tau}^{d}}{P_{t+\tau}}\right)^{-\rho} y_{t+\tau}}
$$

If prices are flexible, and thus $\xi_{p}=0$, then this expression reduces to:

$$
P_{t}^{d}(i)=\frac{\sigma}{\sigma-1} M C_{t}
$$

which says that the firm will set a price equal to a constant mark-up over marginal cost.

Write the domestic price set by the firm that can reset prices in period $t$ as $\tilde{P}_{t}^{d}(i)$ to denote that it is an optimal price. Firms that can reset prices in period $t$ will all reset to the same level, so $\tilde{P}_{t}^{d}(i)=\tilde{P}_{t}^{d}$. Substitute this optimal price into the price index $P_{t}^{d}=\left(\frac{1}{n} \int_{0}^{n}\left(P_{t}^{d}(i)\right)^{1-\sigma} d i\right)^{\frac{1}{1-\sigma}}$. Since a firm has a probability of $1-\xi_{p}$ of being able to change their price, then by the law of large 
numbers in any period $1-\xi_{p}$ percent of firms will reoptimize prices, and the prices of $\xi_{p}$ percent of firms will be automatically reset using the previous periods inflation rate. Thus the domestic price index, $P_{t}^{d}$, can be written as:

$$
P_{t}^{d}=\left(\xi_{p}\left(\Pi_{t-1, t} P_{t-1}^{d}\right)^{1-\sigma}+\left(1-\xi_{p}\right)\left(\tilde{P}_{t}^{d}\right)^{1-\sigma}\right)^{\frac{1}{1-\sigma}}
$$

The full details of this derivation as well as the derivation for prices set for the foreign market is located in the appendix.

The firm hires labor and capital inputs, where $W_{t}$ is the wage rate paid for labor input and $R_{t}$ is the capital rental rate, both of which the firm takes as given. Furthermore the firm must pay their wage bill in advance. To do so they borrow $b_{t}^{w c}(i)=W_{t} h_{t}(i)$. The firm's income after paying for capital and labor inputs is:

$$
d_{t}^{f}(i)=P_{t}^{d}(i) y_{t}^{d}(i)+P_{t}^{x}(i) y_{t}^{x}(i)-W_{t} h_{t}(i)-R_{t} k_{t}(i)-r_{t}^{w c} b_{t}^{w c}(i)
$$

where $P_{t}^{x}(i)$ is the export price for the intermediate good from firm $i$, and $r_{t}^{w c}$ is the interest rate on working capital loans. Since there is no default risk from lending working capital to firms, competition in the banking sector forces the rate on working capital loans down to the bank's own cost of capital, $r_{t}^{w c}=r_{t}^{b}{ }^{6}$

The aggregate income from all firms is returned to households as a lump sum payment, $d_{t}^{f}=$ $\int_{0}^{n} d_{t}^{f}(i) d i$

The firm will choose $h_{t}(i)$ and $k_{t}(i)$ to maximize profit in (5) subject to the production function in (1). The working capital requirement implies that the cost of the labor input is $W_{t}\left(1+r_{t}^{w c}\right)$ and the cost of the capital input is $R_{t}$. Given these prices, the firm's demand for labor and capital inputs are:

\footnotetext{
${ }^{6}$ As will be discussed later in the paper, this implies that a firm's access to short term working capital financing is tied to the health of the banking sector and the bank's cost of funds. When presenting the results we will run alternate simulations of the model where firms can borrow working capital at the risk free rate, and thus a firm's access to short term financing is not tied to the health of the financial system.
} 


$$
\begin{aligned}
h_{t}(i) & =(1-\alpha) \frac{M C_{t}}{W_{t}\left(1+r_{t}^{w c}\right)} Y_{t}(i) \\
k_{t}(i) & =\alpha \frac{M C_{t}}{R_{t}} Y_{t}(i)
\end{aligned}
$$

where $M C_{t}=\frac{1}{A_{t}}\left(\frac{W_{t}\left(1+r_{t}^{w c}\right)}{1-\alpha}\right)^{1-\alpha}\left(\frac{R_{t}}{\alpha}\right)^{\alpha}$.

\subsection{Entrepreneurs}

Entrepreneurs, indexed $j \in[0 n]$, buy capital from capital builders and rent it to firms. At the beginning of period $t$, entrepreneur $j$ has a stock of capital, $K_{t}(j)$, that he will rent to firms in period $t$ at a rental rate $R_{t}$. In equilibrium, the aggregate stock of capital supplied by all domestic entrepreneurs $j$ is equal to the aggregate stock of capital demanded by all domestic firms $i, \int_{0}^{n} K_{t}(j) d j=\int_{0}^{n} k_{t}(i) d i$.

Entrepreneurs finance this stock of capital partially through debt. The entrepreneur borrows $b_{t}^{e}(j)$ from domestic banks to finance their capital stock $K_{t}(j)$. Thus the market value of the assets and liabilities for entrepreneur $j$ at the beginning of period $t$ are:

$$
\begin{aligned}
\text { Assets: } & P_{t}^{K} K_{t}(j) \\
\text { Liabilities: } & b_{t}^{e}(j)
\end{aligned}
$$

where $P_{t}^{K}$ is the price of existing capital.

The end of the period the value of the non-depreciated capital stock for the average entrepreneur is $P_{t}^{K}(1-\delta) K_{t}$. However during the period, the individual entrepreneur $j$ receives an idiosyncratic draw that affects the relative price of their existing capital, so for entrepreneur $j$ the end of period value of their non-depreciated capital stock is:

$$
\omega_{t}^{e}(j) P_{t}^{K}(1-\delta) K_{t}(j)
$$

where $\omega_{t}^{e}(j)$ is a i.i.d. draw from a lognormal distribution on the interval $[0, \infty)$ with mean 1 and variance $\sigma_{e}^{2}$.

Since this draw has a mean 1 , it has no effect on the aggregate capital stock. It simply introduces 
heterogeneity among entrepreneurs, and in any given period a fraction of entrepreneurs receive a draw that has a large adverse effect on the value of their existing capital (a small $\omega_{t}^{e}(j)$ ) and thus at the end of the period, the value of their liabilities exceeds the value of their assets.

During the period the entrepreneur rents his capital stock to firms for a rental rate of $R_{t}$. The entrepreneur finances this capital stock with a loan from the bank with an interest rate $r_{t}^{e}$. Thus at the end of the period, after the realization of $\omega_{t}^{e}(j)$, the nominal market value of entrepreneur $j$ 's assets is $\omega_{t}^{e}(j) P_{t}^{K}(1-\delta) K_{t}(j)+R_{t} K_{t}(j)$. At the end of the period the nominal value of the entrepreneur's liabilities is $\left(1+r_{t}^{e}\right) b_{t}^{e}(j)$.

Thus, after the realization of $\omega_{t}^{e}(j)$, entrepreneur $j$ is bankrupt if:

$$
\omega_{t}^{e}(j) P_{t}^{K}(1-\delta) K_{t}(j)+R_{t} K_{t}(j)<\left(1+r_{t}^{e}\right) b_{t}^{e}(j)
$$

Thus the threshold value of $\omega_{t}^{e}(j)$ below which the entrepreneur goes bankrupt in period $t$ and above which they continue operations is:

$$
\bar{\omega}_{t}^{e}=\frac{\left(1+r_{t}^{e}\right) \frac{b_{t}^{e}(j)}{K_{t}(j)}-R_{t}}{P_{t}^{K}(1-\delta)}
$$

where $D A_{t}^{e}(j)=\frac{b_{t}^{e}(j)}{K_{t}(j)}$ is the ratio of the book value of debt to the book value of assets on an entrepreneur's balance sheet. The history of individual entrepreneur $j$ will influence the level of $b_{t}^{e}(j)$ and $K_{t}(j)$, but the ratio $D A_{t}^{e}(j)=\frac{b_{t}^{e}(j)}{K_{t}(j)}$ is equal across all entrepreneurs. This is a key result for aggregation, for it implies that the bankruptcy cutoff value $\bar{\omega}_{t}^{e}$ does not depend on an entrepreneur's history. More intuition behind this result is presented at the end of this section and a formal proof is presented in the appendix.

If entrepreneur $j$ does not default in period $t$, the creditors receive a return of $r_{t}^{e}$. If the entrepreneur defaults, creditors receive a share of the entrepreneur's remaining assets, less the bankruptcy cost $\mu^{e}$. The threshold value $\bar{\omega}_{t}^{e}$ in equation (9) determines whether or not an entrepreneur goes into default. Thus the payoff to creditors conditional of the realization of the shock $\omega_{t}^{e}(j)$ is:

$$
\begin{array}{cc}
\left(1+r_{t}^{e}\right)\left(b_{t}^{e}(j)\right) & \text { if } \omega_{t}^{e}(j) \geq \bar{\omega}_{t}^{e} \\
\left(1-\mu^{e}\right)\left[\omega_{t}^{e}(j)(1-\delta) P_{t}^{K} K_{t}(j)+R_{t} K_{t}(j)\right] & \text { if } \omega_{t}^{e}(j)<\bar{\omega}_{t}^{e}
\end{array}
$$

Perfect competition in the banking sector implies that the bank's expected profit is zero. So 
the no default rate the bank charges on physical capital loans is set such that the expected return, after factoring in the cost of bankruptcy, is equal to the bank's cost of capital, $r_{t}^{b}$ :

$$
\left(1+r_{t}^{b}\right) b_{t}^{e}(j)=\int_{0}^{\bar{\omega}_{t}^{e}}\left(1-\mu^{e}\right)\left(\omega_{t}^{e}(j)(1-\delta) P_{t}^{K} K_{t}(j)+R_{t} K_{t}(j)\right) d F\left(\omega_{t}^{e}\right)+\int_{\bar{\omega}_{t}^{e}}^{\infty}\left(1+r_{t}^{e}\right) b_{t}^{e}(j) d F\left(\omega_{t}^{e}\right)
$$

where $F\left(\omega_{t}^{e}\right)$ is the c.d.f. of the lognormal distribution of $\omega_{t}^{e}$.

Thus the interest rate charged by banks for physical capital loans is:

$$
1+r_{t}^{e}=\frac{\left(1+r_{t}^{b}\right)}{1-F\left(\bar{\omega}_{t}^{e}\right)}-\frac{\left(1-\mu^{e}\right)\left[R_{t} F\left(\bar{\omega}_{t}^{e}\right)+(1-\delta) P_{t}^{K} \int_{0}^{\bar{\omega}_{t}^{e}} \omega_{t}^{e} d F\left(\omega_{t}^{e}\right)\right]}{\left(1-F\left(\bar{\omega}_{t}^{e}\right)\right) \frac{b_{t}^{e}(j)}{K_{t}(j)}}
$$

where $F\left(\bar{\omega}_{t}^{e}\right)$ is the percent of manufacturing firms that declare bankruptcy.

Holding all else equal, this interest rate, $r_{t}^{e}$, is increasing in $F\left(\bar{\omega}_{t}^{e}\right)$. If there are financial frictions in the entrepreneurial sector, $F\left(\bar{\omega}_{t}^{e}\right)$ is increasing in $\bar{\omega}_{t}^{e} \cdot \bar{\omega}_{t}^{e}$ is increasing in the manufacturing firm's debt-asset ratio. Thus when there are financial frictions in the entrepreneurial sector, the interest rate on physical capital loans is increasing in the level of debt on an entrepreneur's balance sheet.

The cutoff value of $\omega_{t}^{e}(j)$ in equation (9) combined with the interest rate expression in (11) demonstrates the feedback loop associated with financial frictions in the entrepreneurial sector. When the price of existing capital, $P_{t}^{K}$ falls, the cutoff value $\bar{\omega}_{t}^{e}$ rises. This implies that more firms will receive draws of $\omega_{t}^{e}(j)$ below this cutoff value and be forced into bankruptcy. When more firms go into bankruptcy, $F\left(\bar{\omega}_{t}^{e}\right)$ increases, and $r_{t}^{e}$ increases as banks now demand a higher interest rate to compensate for the increased bankruptcy risk. This higher $r_{t}^{e}$ means higher interest expenses and lower profit for the entrepreneur, which leads to a further increase in the cutoff value $\bar{\omega}_{t}^{e}$.

The end of period net worth for the firm that survives is the firm's profit in time $t$ plus the value of their non-depreciated capital stock:

$$
\tilde{N}_{t}^{e}(j)=r_{t}^{k} K_{t}(j)-\left(1+r_{t}^{e}\right) b_{t}^{e}(j)+\omega_{t}^{e}(j) P_{t}^{K}(1-\delta) K_{t}(j)
$$

The firm will pay a dividend to shareholders of $d_{t}^{e}(j)$ and begin the next period with net worth $N_{t+1}^{e}(j)=\tilde{N}_{t}^{e}(j)-d_{t}^{e}(j)$. Firms that declare bankruptcy in period $t$ pay no dividend and drop out of the market, they are replaced with new firms, which are endowed with start up capital of 
$\bar{N}^{e}$. Thus the net worth of the entrepreneurial sector at the beginning of next period is:

$$
\begin{aligned}
N_{t+1}^{e} & =\int_{0}^{\bar{\omega}_{t}^{e}} N_{t+1}^{e}(j) d F\left(\bar{\omega}_{t}^{e}\right)+\int_{\bar{\omega}_{t}^{e}}^{\infty} N_{t+1}^{e}(i) d F\left(\bar{\omega}_{t}^{e}\right) \\
& =\bar{N}^{e} F\left(\bar{\omega}_{t}^{e}\right)+\left(r_{t}^{k} K_{t}-\left(1+r_{t}^{e}\right) b_{t}^{e}-d_{t}^{e}\right)\left(1-F\left(\bar{\omega}_{t}^{e}\right)\right)+P_{t}^{K}(1-\delta) K_{t} \int_{\bar{\omega}_{t}^{e}}^{\infty} \omega_{t}^{e} d F\left(\bar{\omega}_{t}^{e}\right)
\end{aligned}
$$

At the beginning of any period, entrepreneurs have different levels of net worth $N_{t+1}(j)$ that will depend on the entrepreneur's history of idiosyncratic shocks $\omega_{t}^{e}(j)$.

The entrepreneur will acquire capital up to the point where the interest rate on bank loans is equal to the expected return to holding a unit of capital:

$$
r_{t+1}^{e}=E_{t}\left(\frac{R_{t+1}+\omega_{t+1}^{e}(j)(1-\delta) P_{t+1}^{K}}{P_{t}^{K}}\right)
$$

Since $\omega_{t+1}^{e}(j)$ is i.i.d. and $E_{t}\left(\omega_{t+1}^{e}(j)\right)=1$, the left hand side of the above expression is the same across all entrepreneurs $j$, which implies that $r_{t+1}^{e}$ is the same across all entrepreneurs.

\subsection{Capital Builders}

The representative capital builder converts final goods, given by equation (2), into the physical capital purchased by entrepreneurs. At the end of period $t$, the non depreciated physical capital stock is $(1-\delta) K_{t}$, and the physical capital stock at the beginning of the next period is $K_{t+1}$. The evolution of the physical capital stock is given by:

$$
K_{t+1}-(1-\delta) K_{t}=\phi\left(\frac{I_{t}}{K_{t}}\right) K_{t}
$$

where $\phi^{\prime}>0$ and $\phi^{\prime \prime}<0$ implying that there are diminishing marginal returns to physical capital investment. Capital builders purchase final goods for investment at a price $P_{t}$ and sell existing capital to entrepreneurs at a price $P_{t}^{K}$. Thus the profits of the representative capital builder are given by:

$$
d_{t}^{c}=P_{t}^{K}\left(K_{t+1}-(1-\delta) K_{t}\right)-P_{t} I_{t}
$$


In a competitive capital building sector, profit maximization implies that the relative price of existing capital is:

$$
\frac{P_{t}^{K}}{P_{t}}=\left[\phi^{\prime}\left(\frac{I_{t}}{K_{t}}\right)\right]^{-1}
$$

Since $\phi^{\prime \prime}<0$, when $\frac{I_{t}}{K_{t}}$ is high, $\phi^{\prime}\left(\frac{I_{t}}{K_{t}}\right)$ is low, so $\frac{P_{t}^{K}}{P_{t}}$ is high. This implies that during times of high physical capital investment, when the ratio of investment to the existing capital stock is high, the relative price of existing capital is high. Since investment is highly procyclical, capital adjustment costs imply that the relative price of capital is highly procyclical as well.

\subsection{Banks}

Banks, indexed $k \in\left[\begin{array}{ll}0 & n\end{array}\right]$ make physical capital loans to domestic entrepreneurs. They finance this loan portfolio partially with equity and partially with borrowing from domestic and foreign households.

At the beginning of period $t$, the value of the bank's assets is $B_{t}^{e}(k)$, which is the bank's stock of loans to entrepreneurs. The value of the bank's liabilities is $b_{t}^{s}(k)+b_{t}^{s f}(k)$, where $b_{t}^{s}(k)$ are the deposits of domestic households and $b_{t}^{s f}(k)$ are the deposits of foreign households. ${ }^{7}$

The bank also makes working capital loans to firms in order to finance the firm's wage bill. This however is not listed as a beginning of period asset for the bank. By assumption this loan is made after the beginning of the period and repaid before the end of the period. If the stock of working capital loans were to appear as a asset for the bank at the beginning of period $t$, that would imply that the loan was made in period $t-1$, which implies that the firm made a decision about period $t$ 's labor input in period $t-1$.

Bankruptcy in the entrepreneurial sector in period $t$ means the bank's assets are worth less at the end of the period. The value of the average bank's assets at the end of the period is $\left(1-\zeta_{t}^{e}\right)\left(1+r_{t}^{e}\right) B_{t}^{e}$, where $\zeta_{t}^{e}$ is the share of the average bank's physical capital loan portfolio that is lost to bankruptcy and liquidation costs.

\footnotetext{
${ }^{7}$ The same stock of bonds that is a liability to one party is an asset to another. Throughout this paper, when a stock of bonds is an asset, it is written with a capital $B$, when the stock of bonds is a liability it is written with a lower case $b$.

Thus market clearing in the bond market requires that the sum of physical capital loans across all banks equals the sum of borrowing by entrepreneurs, $\int_{0}^{n} B_{t}^{e}(k) d k=\int_{0}^{n} b_{t}^{e}(j) d j$.
} 
$\zeta_{t}^{e}$ represents the share of the average bank's physical capital loan portfolio that is lost to bankruptcy and liquidation costs, however banks don't hold fully diversified loan portfolios. Some banks may be overexposed to the set of non-performing loans to the entrepreneurial sector. This overexposure may be due to a regional bias in the bank's portfolio, or it may be because a bank has a certain core competency and is therefore overexposed to a certain sector of the economy. ${ }^{8}$

The percent of the bank $k$ 's loan portfolio that is lost to bankruptcy or liquidation costs is $\omega_{t}^{b}(k) \zeta_{t}^{e}$, where $\omega_{t}^{b}(k)$ is an i.i.d. draw from a lognormal distribution on the interval $\left[0 \frac{1}{\zeta_{t}^{e}}\right]$ with mean 1 and standard deviation $\sigma_{t}^{b}$.

If bank $k$ receives a large draw $\omega_{t}^{b}(k)$, it implies that the bank is overexposed to the set of non-performing loans and may itself face insolvency. The bank is insolvent if the end of period value of its assets is less than the end of period value of its liabilities:

$$
\left(1-\omega_{t}^{b}(k) \zeta_{t}^{e}\right)\left(1+r_{t}^{e}\right) B_{t}^{e}(k)<\left(1+r_{t}^{b}(k)\right)\left(b_{t}^{s}(k)+b_{t}^{s f}(k)\right)
$$

The threshold value of $\omega_{t}^{b}(k)$ above which bank $k$ is forced to declare bankruptcy and below which the bank will continue operations is:

$$
\bar{\omega}_{t}^{b}=\frac{\left(1+r_{t}^{e}\right)-\left(1+r_{t}^{b}(k)\right) \frac{b_{t}^{s}(k)+b_{t}^{s f}(k)}{B_{t}^{e}(k)}}{\zeta_{t}^{e}\left(1+r_{t}^{e}\right)}
$$

Bank $k$ 's history of idiosyncratic draws, $\omega_{t}^{b}(k)$, thus its history of exposure to non-preforming sectors of the economy, will determine the levels of $B_{t}^{e}(k), b_{t}^{s}(k)$, and $b_{t}^{s f}(k)$. However, at the beginning of the period, all banks will have the same ratio of total debt to total assets, $D A_{t}^{b}(k)=$ $\frac{b_{t}^{s}(k)+b_{t}^{s f}(k)}{B_{t}^{e}(k)}$ and will have the same cost of capital, $r_{t}^{b}(k)$. This result is key for the aggregation of balance sheet variables across a continuum of individual banks, for this implies that the cutoff value $\bar{\omega}_{t}^{b}$ is common across all banks. The formal proof of this claim is presented in the appendix.

When deciding how much to lend to bank $k$ in the next period and at what rate, the bank's creditors factor in the fact that if the bank does not default, they receive a gross interest rate $1+r_{t+1}^{b}(k)$. If bank $k$ defaults, creditors receive nothing. ${ }^{9}$ Thus the expected payoff to a bank's

\footnotetext{
${ }^{8}$ Like the banks, many of which are now bankrupt or were acquired by healthier rivals, who were overexposed to the subprime sector of the mortgage market during the recent financial crisis.

${ }^{9}$ The assumption that creditors receive nothing in the case of bank default is because the model is later calibrated such that the spread between the interbank rate, $r^{b}$, and the risk free rate, $i$, in the steady state of the model is equal
} 
creditors conditional on the bank's exposure to the set of non-preforming loans is:

$$
\begin{array}{cl}
\left(1+r_{t+1}^{b}(k)\right)\left(b_{t+1}^{s}(k)+b_{t+1}^{s f}(k)\right) & \text { if } \omega_{t+1}^{b}(k)<\bar{\omega}_{t+1}^{b} \\
0 & \text { if } \omega_{t+1}^{b}(k) \geq \bar{\omega}_{t+1}^{b}
\end{array}
$$

Domestic and foreign depositors will extend bank $k$ credit up to the point where the expected return, after factoring in the probability of default is equal to the risk free rate:

$$
\left(1+i_{t+1}\right)\left(b_{t+1}^{b}(k)+b_{t+1}^{b f}(k)\right)=\int_{0}^{\bar{\omega}_{t+1}^{b}}\left(1+r_{t+1}^{b}(k)\right)\left(b_{t+1}^{b}(k)+b_{t+1}^{b f}(k)\right) d G\left(\omega_{t+1}^{b}\right)
$$

This condition can be used to solve for the interest rate on interbank lending to bank $k$ :

$$
1+r_{t+1}^{b}(k)=\frac{1+i_{t+1}}{G\left(\bar{\omega}_{t+1}^{b}\right)}
$$

where $G\left(\bar{\omega}_{t+1}^{b}\right)$ is the c.d.f. of the lognormal distribution of $\bar{\omega}_{t+1}^{b}$, and thus measures the proportion of banks that do not go bankrupt in period $t+1$. Since $D A_{t+1}^{b}(k)=\frac{b_{t+1}^{s}(k)+b_{t+1}^{s f}(k)}{B_{t+1}^{e}(k)}$ is constant across all banks, the interbank lending rate, and thus banks' cost of capital, is constant across all banks.

The expressions for the cutoff value $\bar{\omega}_{t+1}^{b}$ in (13) and the interbank interest rate in (15) shows how the feedback loop mentioned earlier that occurs because of bankruptcy risk in the entrepreneurial sector is worse when we also consider insolvency risk in the banking sector.

If the expected bankruptcy rate in the real sector is high, the expected loan losses for the average bank, $E_{t}\left(\zeta_{t+1}^{e}\right)$, is high. When $E_{t}\left(\zeta_{t+1}^{e}\right)$ increases, $\bar{\omega}_{t+1}^{b}$ decreases. If bank $k$ receives a draw of $\omega_{t+1}^{b}(k)$ above $\bar{\omega}_{t+1}^{b}$, then the bank is overexposed to the set of non-performing loans and that bank becomes insolvent. When $\bar{\omega}_{t+1}^{b}$ falls, more banks are expected to receive a draw above the cutoff value, and thus the expectation of more insolvencies in the real sector lead to the expectation of more insolvencies in the financial sector. The greater chance of insolvency causes an increase in interbank interest rates, $r_{t+1}^{b} \cdot{ }^{10}$

to the historical average of the spread between the 3-month Libor and the 3-month T-bill. The Libor is an interbank index rate that is based on the interest rate for unsecured lending to banks.

${ }^{10} \mathrm{An}$ increase in $E_{t}\left(\zeta_{t+1}^{e}\right)$ can be thought of as the special kind of bad news discussed in Geanakoplos (2009). An increase in aggregate loan losses not only lowers expectations about the value of a bank's assets, but it leads to more uncertainty about the value as well. 
When interbank interest rates increase, banks are forced to pass on this higher cost of capital by charging higher interest rates on loans to the entrepreneurial sector. This squeezes entrepreneurial sector balance sheets, as discussed earlier in section 2.2 , leading to more bankruptcies in the entrepreneurial sector. Thus a second feedback loop occurs due to frictions in the banking sector that compliments the earlier feedback loop that was due to frictions in the entrepreneurial sector.

The end of period $t$ net worth of the bank that is not over-exposed to the set of non-preforming loans and is able to continue operations is:

$$
\tilde{N}_{t}^{b}=\left(1-\omega_{t}^{b}(k) \zeta_{t}^{e}\right)\left(1+r_{t}^{e}\right) B_{t}^{e}(k)-\left(1+r_{t}^{b}\right)\left(b_{t}^{s}(k)+b_{t}^{s f}(k)\right)
$$

The bank will pay a dividend to shareholders and begin the next period with a net worth $N_{t+1}^{b}(k)=\tilde{N}_{t}^{b}(k)-d_{t}^{b}(k)$. Banks that were overexposed to the set of non-preforming loans and thus were forced into bankruptcy end the period with no net worth and drop out of the market. They are replaced with new banks that are endowed with start up capital $\bar{N}^{b}$. Thus the net worth of the entire banking sector at the beginning of next period is:

$$
\begin{aligned}
N_{t+1}^{b}= & \int_{\bar{\omega}_{t}^{b}}^{\infty} N_{t+1}^{b}(i) d G\left(\omega_{t}^{b}\right)+\int_{0}^{\bar{\omega}_{t}^{b}} N_{t+1}^{b}(k) d G\left(\omega_{t}^{b}\right) \\
= & \bar{N}^{b}\left(1-G\left(\bar{\omega}_{t}^{b}\right)\right)+\left(\left(1+r_{t}^{e}\right) B_{t}^{e}-\left(1+r_{t}^{b}\right)\left(b_{t}^{s}+b_{t}^{s f}\right)-d_{t}^{b}\right) G\left(\bar{\omega}_{t}^{b}\right) \\
& -\left(1+r_{t}^{e}\right) B_{t}^{e} \zeta_{t}^{e} \int_{0}^{\bar{\omega}_{t}^{b}} \omega_{t}^{b} d G\left(\omega_{t}^{b}\right)
\end{aligned}
$$

\subsection{Households}

Households, indexed $l \in[0 \mathrm{n}]$, supply heterogeneous labor to firms and consume from their labor income, interest on savings, and profit income from firms, entrepreneurs, capital builders, and banks.

The household maximizes their utility function:

$$
\max \sum_{t=0}^{\infty} \beta^{t}\left[\ln \left(C_{t}(l)\right)-\psi\left(H_{t}(l)\right)^{\frac{1+\sigma_{H}}{\sigma_{H}}}\right]
$$

subject to their budget constraint: 


$$
\begin{aligned}
& P_{t} C_{t}(l)+B_{t+1}^{s}(l)+S_{t} B_{t+1}^{s f *}(l)+F\left(\bar{\omega}_{t}^{e}\right) \bar{N}^{e}+\left(1-G\left(\bar{\omega}_{t}^{b}\right)\right) \bar{N}^{b} \\
= & W_{t}(l) H_{t}(l)+d_{t}^{f}(l)+d_{t}^{e}(l)+d_{t}^{c}(l)+d_{t}^{b}(l)+\left(1-\zeta_{t}^{b}\right)\left(1+r_{t}^{b}\right) B_{t}^{s}(l) \\
& +\left(1-\zeta_{t}^{b *}\right)\left(1+r_{t}^{b *}\right) S_{t} B_{t}^{s f *}(l)+\zeta_{t}^{e}+\zeta_{t}^{b}-\frac{\chi^{b}}{2}\left(S_{t} B_{t}^{s f *}(l)-S_{t} \bar{B}^{s f *}\right)^{2}
\end{aligned}
$$

where $C_{t}(l)$ is consumption by household $l$ in period $t, H_{t}(l)$ is the household's labor effort in the period, $B_{t}^{s}(l)$ is the household's stock of deposits with domestic banks at the beginning of the period, $B_{t}^{s f *}(l)$ is the stock of deposits with foreign banks, $W_{t}(l)$ is the wage paid for the household's heterogenous labor supply, $\zeta_{t}^{b}\left(\zeta_{t}^{b *}\right)$ represents the small share of deposits to the home (foreign) banking sector that are lost to bankruptcy and liquidation costs, and $d_{t}^{f}(l), d_{t}^{e}(l), d_{t}^{c}(l)$ and $d_{t}^{b}(l)$ are the household's share of period $t$ profits from firms, entrepreneurs, capital builders and banks, respectively. ${ }^{11}$

The household pays a small quadratic transactions cost to holding other than the steady state level of deposits with foreign banks, $\frac{\chi^{b}}{2}\left(B_{t}^{s f *}(l)-\bar{B}^{s f *}\right)^{2}$.

Each household supplies a differentiated type of labor. The function to aggregate the labor supplied by each household into the aggregate stock of labor employed by domestic firms is:

$$
H_{t}=\left(\int_{0}^{n} H_{t}(l)^{\frac{\theta-1}{\theta}} d l\right)^{\frac{\theta}{\theta-1}}
$$

where $H_{t}=\int_{0}^{n} h_{t}(i) d i$. Since the household supplies a differentiated type of labor, it faces a downward sloping labor demand function:

$$
H_{t}(l)=\left(\frac{W_{t}(l)}{W_{t}}\right)^{-\theta} H_{t}
$$

In any given period, household $j$ faces a probability of $1-\xi_{w}$ of being able to reset their wage, otherwise it is reset automatically according to $W_{t}(l)=\pi_{t-1} W_{t-1}(l)$.

If household $j$ is allowed to reset their wages in period $t$ they will set a wage to maximize the

\footnotetext{
${ }^{11}$ Market clearing in the market for deposits requires that the sum of deposits with domestic banks across all domestic households equals the sum of borrowing from domestic households across all domestic banks, $\int_{0}^{n} B_{t}^{s}(l) d l=$ $\int_{0}^{n} b_{t}^{s}(k) d k$, and that the sum of deposits with foreign banks across all domestic households equals the sum of borrowing from domestic households across all foreign banks, $\int_{0}^{n} B_{t}^{s f *}(l) d l=\int_{n}^{1} b_{t}^{s f *}(k) d k$.
} 
expected present value of utility from consumption minus the disutility of labor.

$$
E_{t} \sum_{\tau=0}^{\infty} \beta^{\tau}\left(\xi_{w}\right)^{\tau}\left\{\lambda_{t+\tau} \Pi_{t, t+\tau} W_{t}(l) H_{t+\tau}(l)-\psi\left(H_{t+\tau}(l)\right)^{\frac{1+\sigma_{H}}{\sigma_{H}}}\right\}
$$

Thus after technical details which are located in the appendix, the household that can reset wages in period $t$ will choose a wage:

$$
W_{t}(l)^{\frac{\theta}{\sigma_{H}}+1}=\frac{\theta}{\theta-1} \frac{1+\sigma_{H}}{\sigma_{H}} \psi\left(W_{t}\right)^{\frac{\theta}{\sigma_{H}}} \frac{E_{t} \sum_{\tau=0}^{\infty} \beta^{\tau}\left(\xi_{w}\right)^{\tau}\left(\frac{W_{t+\tau}}{\Pi_{t, t+\tau} W_{t}}\right)^{\frac{\theta}{\sigma_{H}}+\theta}\left(H_{t+\tau}\right)^{\frac{1+\sigma_{H}}{\sigma_{H}}}}{E_{t} \sum_{\tau=0}^{\infty} \beta^{\tau}\left(\xi_{w}\right)^{\tau} \lambda_{t+\tau} \Pi_{t, t+\tau}\left(\frac{W_{t+\tau}}{\Pi_{t, t+\tau} W_{t}}\right)^{\theta} H_{t+\tau}}
$$

If wages are flexible, and thus $\xi_{w}=0$, this expression reduces to:

$$
W_{t}(l)=\frac{\theta}{\theta-1} \frac{\frac{1+\sigma_{H}}{\sigma_{H}} \psi\left(H_{t}\right)^{\frac{1}{\sigma_{H}}}}{\lambda_{t}}
$$

Thus when wages are flexible the wage rate is equal to a mark-up, $\frac{\theta}{(\theta-1)}$, multiplied by the marginal disutility of labor, $\frac{1+\sigma_{H}}{\sigma_{H}} \psi\left(H_{t}\right)^{\frac{1}{\sigma_{H}}}$, divided by the marginal utility of consumption, $\lambda_{t}$.

Write the wage rate for the household that can reset wages in period $t, W_{t}(l)$, as $\tilde{W}_{t}(l)$ to denote it as an optimal wage. Also note that all households that can reset wages in period $t$ will reset to the same wage rate, so $\tilde{W}_{t}(l)=\tilde{W}_{t}$.

All households face a probability of $\left(1-\xi_{w}\right)$ of being able to reset their wages in a given period, so by the law of large numbers $\left(1-\xi_{w}\right)$ of households can reset their wages in a given period. The wages of the other $\xi_{w}$ will automatically reset by the previous periods inflation rate.

Substitute $\tilde{W}_{t}$ into the expression for the average wage rate $W_{t}=\left(\int_{0}^{n} W_{t}(l)^{1-\theta} d l\right)^{\frac{1}{1-\theta}}$, to derive an expression for the evolution of the average wage:

$$
W_{t}=\left(\xi_{w}\left(\Pi_{t-1, t} W_{t-1}\right)^{1-\theta}+\left(1-\xi_{w}\right)\left(\tilde{W}_{t}\right)^{1-\theta}\right)^{\frac{1}{1-\theta}}
$$

\subsection{Monetary Policy}

The monetary policy instrument is the short term risk free rate, $i_{t}$, which is determined by the central bank's Taylor rule function: 


$$
\frac{1+i_{t}}{1+i^{s s}}=\left(\frac{1+i_{t-1}}{1+i^{s s}}\right)^{\theta_{i}}\left\{\left(\pi_{t}\right)^{\theta_{p}}\left(1+O G_{t}\right)^{\theta_{y}}\right\}^{1-\theta_{i}} m_{t}
$$

where $\pi_{t}=\frac{P_{t}}{P_{t-4}}, O G_{t}=\frac{G D P_{t}}{A_{t} G D P_{s s}}-1$, and $m_{t}$ is an exogenous shock to the nominal interest rate.

\section{Parameter Values}

The model in the previous section is solved with a first-order approximation and the results are found from simulations of the calibrated model. This section will begin by presenting the basic parameter values used in this calibration. Then we will describe the various types of exogenous shocks that will drive the simulations of the model and the estimation of these different shock processes.

The full list of the model's parameters and their values is found in table 1 .

The first eight parameters: the discount factor, the capital depreciation rate, capital's share of income, the elasticity of substitution between home and foreign goods, the bond adjustment cost parameter, the labor supply elasticity, the elasticity of substitution between goods from different firms, and the elasticity of substitution between labor from different households are all set to values that are commonly found in the literature.

The capital adjustment cost parameter, $\kappa$, describes the curvature of the capital adjustment

function $\phi\left(\frac{I_{t}}{K_{t}}\right)$. It is the elasticity of the relative price of capital with respect to changes in the investment-capital ratio. This parameter preforms the important functions of lowering the relative volatility of investment and ensuring the procyclicality of the price of capital. Empirical estimates of this parameter vary, but the value of 0.375 is in the middle of the range of empirical estimates and ensures that the relative volatility of investment in the model is near what we see in the data.

The next two parameters in the table are the Calvo price and wage stickiness parameters. The wage stickiness parameter is chosen such that on average a household adjusts their wages once a year. The price stickiness parameter implies that prices are a little more flexible than wages and is taken from the DSGE estimation literature (see e.g. Christiano et al. 2005).

The next set of parameters describe exponents in the central bank's Taylor rule function. The interest rate smoothing parameter, the weight on lagged inflation, and the weight on the output gap are all set to values that are commonly found in the literature. 
The next four parameters are all determined so that the steady state of the model is able to match certain features of the data. The $\gamma$ and $\gamma^{f}$ parameters from the function that aggregates home and foreign goods in (2) are set such that the home country in the model has a steady state import share of $25 \%$. Note that this value will depend on whether we are considering the closed, the large open, or the small open economy. ${ }^{12}$ The next two parameters, $\phi$ and $\psi$ are the fixed cost in the production of intermediate goods and the weight on the disutility from labor in the household's utility function, respectively. These are set to ensure that in the steady state, intermediate goods firms earn zero economic profit and the household's labor supply is unity.

Finally the last three parameters in the table relate to the risk of bankruptcy and liquidation costs in either the banking or entrepreneurial sectors. The parameter $\sigma_{t}^{b}$ measures the steady state level of uncertainty in the financial sector. This parameter is determined to ensure that in the steady state of the model, when banks have a debt-asset ratio of about 0.9 , there is a 13 basis point spread between interbank rates and the risk free rate, the average spread between the 3-month Libor and the 3-month T-bill from 1984 to 2007.

The cost of liquidation and the idiosyncratic bankruptcy risk in the entrepreneurial sector, $\mu^{e}$ and $\sigma_{e}$ are jointly determined. These parameters ensure that in the steady state of the model, when firms in the entrepreneurial sector have a debt-asset ratio of 0.5 , an entrepreneur faces a $2 \%$ probability of bankruptcy and the steady state spread between the interest rate on physical capital loans and the bank's cost of capital is approximately 70 basis points. ${ }^{13}$

\subsection{Exogenous Shock Processes}

In this model there are three types of shocks. The first two, country specific shocks to total factor productivity (TFP) in (1) and country specific monetary policy shocks that appear in the central bank's Taylor rule function in (20) are common features of many real business cycle or new Keynesian models. The third shock is a shock to the uncertainty about the health of a bank's

\footnotetext{
${ }^{12}$ From the demand functions for domestically supplied intermediate inputs and imports, equations (3) and (4), the steady state import share is: $m=\frac{\int_{n}^{1} P_{t}^{m}(i) y_{t}^{m}(i)}{\int_{0}^{n} P_{t}^{d}(i) y_{t}^{d}(i)+\int_{n}^{1} P_{t}^{m}(i) y_{t}^{m}(i)}=\frac{\gamma^{f}(1-n)^{\frac{1-\rho}{1-\sigma}}}{\gamma(n)^{\frac{1-\rho}{1-\sigma}+\gamma^{f}(1-n)^{\frac{1-\rho}{1-\sigma}}}}$

${ }^{13}$ The calibration that entrepreneurs have a steady state debt-asset ratio of about 0.5 and banks have a steady state debt-asset ratio of about 0.9 is based on the historical average debt-asset ratios for U.S. non-financial and financial firms as reported in the Federal Reserve's Flow of Funds Accounts.
} 
assets, $\sigma_{t}^{b}$, and is unique to a model with financial frictions in the banking sector. ${ }^{14}$ Recall that $\sigma_{t}^{b}$ measures the cross-sectional heterogeneity among banks with regard to their exposure to loan losses. This term can also be thought of as the uncertainty about a particular bank's exposure to the set of non-preforming loans. Holding all else equal, an increase in $\sigma_{t}^{b}$ will cause creditors to demand a higher rate when lending to banks. Thus a shock to $\sigma_{t}^{b}$ is a direct shock to the cost of capital in the banking sector.

However before we consider this new and unfamiliar type of shock, let's discuss the estimation of the processes governing TFP and monetary policy shocks.

Shocks to TFP are given by:

$$
\hat{A}_{t}=\hat{Y}_{t}-(1-\alpha) \hat{N}_{t}-\alpha \hat{K}_{t}
$$

where $\hat{Y}_{t}, \hat{N}_{t}$, and $\hat{K}_{t}$, are country-specific time series of deviations of GDP, employment, and the capital stocks, from an HP filtered trend. The series for home and foreign TFP fluctuations are then used to estimate a $\operatorname{VAR}(1)$ process:

$$
\left[\begin{array}{c}
\hat{A}_{t+1} \\
\hat{A}_{t+1}^{*}
\end{array}\right]=\boldsymbol{\rho}^{A}\left[\begin{array}{c}
\hat{A}_{t} \\
\hat{A}_{t}^{*}
\end{array}\right]+\left[\begin{array}{c}
\hat{\varepsilon}_{t}^{a} \\
\hat{\varepsilon}_{t}^{a *}
\end{array}\right]
$$

where $\boldsymbol{\Omega}^{A}=\left[\begin{array}{c}\hat{\varepsilon}_{t}^{a} \\ \hat{\varepsilon}_{t}^{a *}\end{array}\right]\left[\begin{array}{c}\hat{\varepsilon}_{t}^{a} \\ \hat{\varepsilon}_{t}^{a *}\end{array}\right]^{\prime}$ is the covariance matrix of the innovations, $\hat{\varepsilon}_{t}^{a}$ and $\hat{\varepsilon}_{t}^{a *}$.

Alternatively we can consider shocks to the risk free interest rate in the central bank's Taylor rule function. First taking the log of each side of the of the policy function in (20):

$$
\left(i_{t}-i_{s s}\right)=\theta_{i}\left(i_{t-1}-i_{s s}\right)+\left(1-\theta_{i}\right)\left(\theta_{p} \pi_{t}+\theta_{y} O G_{t}\right)+m_{t}
$$

where $i_{t}, \pi_{t}$, and $O G_{t}$ are country specific time series of the overnight interest rate, the inflation rate, and the output gap. Apply the benchmark parameterization, $\theta_{i}=0.9$ and $\theta_{p}=1.5$ and $\theta_{y}=0.5$ to calculate the residual term $m_{t}$, which is a time series of country specific monetary policy shocks.

\footnotetext{
${ }^{14}$ Recently authors have begun to incorporate risk shocks into financial accelerator models, see references in section 4.3 for examples.
} 
The series for home and foreign monetary policy shocks are then used to estimate a VAR(1) process:

$$
\left[\begin{array}{c}
m_{t+1} \\
m_{t+1}^{*}
\end{array}\right]=\boldsymbol{\rho}^{M}\left[\begin{array}{c}
m_{t} \\
m_{t}^{*}
\end{array}\right]+\left[\begin{array}{c}
\hat{\varepsilon}_{t}^{m} \\
\hat{\varepsilon}_{t}^{m *}
\end{array}\right]
$$

where $\boldsymbol{\Omega}^{M}=\left[\begin{array}{c}\hat{\varepsilon}_{t}^{m} \\ \hat{\varepsilon}_{t}^{m *}\end{array}\right]\left[\begin{array}{c}\hat{\varepsilon}_{t}^{m} \\ \hat{\varepsilon}_{t}^{m *}\end{array}\right]^{\prime}$ is the covariance matrix of the innovations, $\hat{\varepsilon}_{t}^{m}$ and $\hat{\varepsilon}_{t}^{m *}$.

Since we consider three types of models, a closed economy, two large open economies, and a small open economy, we need to estimate a few shock processes. The shock processes for the model with two large open economies is estimated from data for the U.S. and the Eurozone from 1995:1 to 2007:2. The processes for the small open economy and the closed economy are estimated from data for the U.S. and the UK from 1984:1 to 2007:2. We treat the U.S. as the large economy and the UK as the small economy. We impose the restriction that there is no spillover from the UK to the U.S. (one of the off-diagonal terms in $\boldsymbol{\rho}^{A}$ and $\boldsymbol{\rho}^{M}$ is equal to zero. This restriction means that the estimated shock processes for the UK are for a small open economy and those for the U.S. are for a closed economy. The processes for the TFP and monetary policy shocks are presented in table 2 .

Since the financial sector uncertainty shocks, $\sigma_{t}^{b}$, are new and unfamiliar, we will not attempt to estimate a process for these shocks but will instead test the model's reaction to a financial sector uncertainty shock under a number of alternative parameterizations.

\section{Results}

To show the cyclical effects of the feedback loop caused by frictions in both the entrepreneurial and banking sectors, we will first discuss some impulse responses to examine the impact of a shock on balance sheets and the see how in a model with financial frictions, balance sheet changes have real effects. Secondly, in an attempt to quantify the feedback loop resulting from financial frictions, we will see how certain second moments of the business cycle (volatility and co-movement) are affected by the introduction of financial frictions into the model. Lastly, we will introduce financial sector risk shocks into the model and show how in an environment with financial frictions in the banking 
sector, exogenous fluctuations in risk arising out of the financial sector can be an independent source of fluctuations.

In what follows we will present the results from three versions of the model, a version where the financial frictions in both the entrepreneurial and banking sectors have been "turned off" and thus the conditions of the Miller and Modigliani theorem hold, where the financial friction in the entrepreneurial sector has been "turned on" but still there are no frictions in the banking sector, and a version where there are frictions in both sectors. When a financial friction is "turned off",

the risk spread, $r_{t}^{e}-r_{t}^{b}$ or $r_{t}^{b}-i_{t}$ is held at its steady state level through dynamic simulations of the model. The steady state value of the spread, and thus the other variables in the model, is the same in all three versions of the model, whether or not the financial friction is "turned on" or "turned off".

\subsection{Impulse Responses}

\subsubsection{The adverse feedback loop in a closed economy}

The responses of the relative price of capital, entrepreneurial sector debt-asset ratios, the risk spread on physical capital loans, and the interbank lending spread in a closed economy to monetary policy shock are presented in figure 1. Following an exogenous increase in the risk free rate, the relative price of capital falls due to the capital adjustment costs that impose diminishing marginal returns to investment. When investment falls, as it does following an exogenous increase in interest rates, the marginal return to investment increases, so the relative price of existing capital falls.

This $1 \%$ fall in the relative price of capital leads to a similar increase in entrepreneurial sector debt-asset ratio. When there are no financial frictions in the model, balance sheets don't matter and this increased leverage has no effect, but when there are financial frictions in the model, this increase in borrower leverage makes lending to entrepreneurs appear riskier. Thus when there are financial frictions in the model, the default risk premium charged by banks increases by $15-20$ basis points.

The increase in entrepreneurial leverage leads to more loan defaults. This leads to a fall in the value of assets on a bank's balance sheet and thus leads to a decline in a bank's net worth. In a model with financial frictions in the banking sector, this make banks appear riskier. The figure 
shows that when financial frictions are present in the banking sector, the monetary policy shock leads to a 10 basis point increase in interbank lending spreads.

Thus the model with financial frictions in both the entrepreneurial and banking sectors predicts that the spread between the rate entrepreneurs pay on physical capital loans and the risk free rate should increase by about 30 basis points in response to an exogenous increase in the risk free rate. When financial frictions are modeled only in the entrepreneurial sector, the total spread increases by about 15 basis points.

The macroeconomic impact of this increase in lending spreads is presented in figure 2 . The figure presents the responses of $G D P$, inflation, investment, and consumption to the same monetary policy shock.

Since financial frictions primarily affect the supply of loanable funds, not surprisingly, investment is the component of GDP that reacts most strongly to the presence of financial frictions in the model. When there are no financial frictions, there is no increase in lending spreads following the exogenous increase in the risk free rate, and investment falls by about $2 \%$. When there are frictions in the entrepreneurial sector but not in the banking sector, the spread between physical capital loan rates and the risk free rate increases by about 15 basis points and this leads to a further $1 \%$ fall in investment. When there are also financial frictions in the banking sector the larger increase in spreads cause investment to fall by about $4 \%$.

The figure goes on to show that this drop in investment leads to a $1.25 \%$ fall in GDP following the shock when there are no financial frictions. However the figure also shows that when there are frictions in both the entrepreneurial and banking sectors, the monetary policy shock results in a $1.5 \%$ fall in $G D P$.

The responses of the same variables to a negative TFP shock are presented in figures 3 and 4 . The chain of events is the same, although the magnitude of the effect due to the financial frictions is much smaller. The TFP shock leads to a fall in output and investment demand. This leads to a fall in the relative price of capital. The fall in the relative price of capital squeezes balance sheets in the entrepreneurial sector, and this leads to higher default risk spreads and more defaults in the model with financial frictions. 


\subsection{Business cycle volatility and co-movement}

The volatility and co-movement of $G D P$, the components of $G D P$, inflation, employment, risk spreads, and the real exchange rate in a model where business cycles are driven by monetary policy shocks are presented in table 3. The same results from the model where business cycles are driven by TFP shocks are presented in table 4 . Each table presents the results for the closed economy, the large open economy, and the small open economy. Furthermore, each table presents the results from the three versions of the model: the version without financial frictions, the version with financial frictions only in the entrepreneurial sector, and the version with financial frictions in both the entrepreneurial and banking sectors.

In each of the three models (the closed economy, the large open economy, and the small open economy), moving from the first column to the second represents moving from a version of the model without financial frictions, where the conditions of the Miller and Modigliani theorem hold, to a version of the model with financial frictions in the entrepreneurial sector, like Bernanke et al. (1999). However in both versions, there are no frictions in the banking sector and the banking sector is simply a "veil". The tables show that introducing financial frictions in the entrepreneurial sector leads to about a $8 \%$ increase in $G D P$ volatility in the model where business cycles are driven by monetary policy shocks and a $2 \%$ increase in volatility under productivity shocks.

Moving from the second column to the third column in each table represents "turning on" the financial frictions in the banking sector. Thus the third column represents the version of the model where the banking sector is not simply a veil and financial conditions within the banking sector can have macroeconomic effects. When business cycles are driven by monetary policy shocks, introducing financial frictions in the banking sector leads to a $10-12 \%$ increase in GDP volatility under monetary policy shocks. In the model with productivity shocks, introducing financial frictions in the banking sector leads to $3 \%$ increase in GDP volatility over the model with frictions only in the entrepreneurial sector.

Since the financial frictions in the model primarily affect the price and availability of loanable funds, introducing financial frictions in the model leads to a significant increase in the relative volatility of investment. Table 3 shows that when business cycles are driven by monetary policy shocks, introducing financial frictions in the entrepreneurial sector leads to about a $25 \%$ increase 
in the relative volatility of investment and frictions in the banking sector lead to a further $10 \%$ increase.

Tables 3 and 4 show that the cyclicality of most macro variables is not strongly affected by the introduction of financial frictions. In the model with the closed economy, the large open economy, and the small open economy under both productivity shocks and monetary policy shocks, the correlation between most variables and GDP does not show any significant change between the model without financial frictions and those with frictions. It is interesting to note the cyclicality of the lending spreads, $r_{t}^{e}-r_{t}^{b}$ and $r_{t}^{b}-i_{t}$, and how the correlation between spreads and GDP depends partially on the type of shock driving business cycle fluctuations.

In all versions of the model, when there are financial frictions in either the entrepreneurial sector alone or both the entrepreneurial and banking sectors, there is a strong negative co-movement between lending spreads and $G D P$. The fact that loanable funds become less available and more expensive during an economic downturn is the essence of the financial accelerator mechanism. However this negative co-movement is much stronger when business cycles are driven by monetary policy shocks than when they are driven by productivity shocks. This fact lies behind the finding throughout this paper that the financial accelerator mechanism is stronger in the model with monetary shocks than in the model with productivity shocks, and it is closely related to the fact that inflation and output are positively correlated under monetary policy shocks and negatively correlated under productivity shocks. This result will be explored in more depth in the next section.

The tables also show how the feedback loop generated by financial frictions leads to a slight increase in international business cycle correlation. Under monetary policy shocks, the introduction of financial frictions in the entrepreneurial and banking sectors leads to about a 3 percentage point increase in cross-country GDP co-movement between two large open economies and about a 2 percentage point increase between a small open economy and the rest of the world. Under productivity shocks the marginal effect of introducing financial frictions leads to a 1 percentage point increase in $G D P$ correlation.

That the introduction of the financial accelerator has only a slight affect on international business cycle co-movement may seem puzzling, for this seems to contrast with recent papers like Dedola and Lombardo (2009), Devereux and Yetman (2010) and Ueda (2010), which incorporate a financial accelerator into an international business cycle model and find that the introduction 
of debt-elastic interest premiums or borrower leverage constraints seem to enhance the degree of international shock propagation. However these models are interested in the role of international financial integration in leading to greater international business cycle transmission. This paper abstracts from the role of international financial integration. In this model, the financial accelerator leads to greater business cycle co-movement simply because it amplifies the effect of shocks already propagated through the usual real channels (like international trade).

\subsubsection{The effect of indexed bond contracts}

In the model, as in most developed countries that have had a history of relatively stable prices, bond contracts are written in nominal terms. Anticipated inflation is factored into the interest rate on the bond, but by its very nature, unanticipated inflation is not factored into the ex-ante bond contract and thus unanticipated inflation affects the real value of the bond. This effect, highlighted in Fisher (1933), is that positive unanticipated inflation reduces the real value of nominal debt contracts and negative unanticipated inflation increases the real value of nominal contracts.

Thus positive unanticipated inflation results in the transfer of resources from the lender to the borrower, and negative unanticipated inflation has the opposite effect. If there are no financial frictions and balance sheets don't matter, the net gain for one group will be canceled out by a net loss for another and unanticipated price movements will have no macroeconomic effect. ${ }^{15}$ If, however, borrowers face financial frictions and balance sheets matter then positive unanticipated inflation that reduces the real value of debt will improve the borrower's balance sheet and reduce their riskiness. All else equal, unanticipated inflation should lower risk spreads and stimulate economic activity.

When balance sheets matter, unanticipated inflation in response to a shock will lead to a "Fisher debt-deflation channel" (Christiano et al., 2008) that will strengthen the financial accelerator following a shock that leads to a positive co-movement between inflation and GDP (a monetary shock) and will dampen the financial accelerator following a shock that results in a negative co-movement (a productivity shock).

\footnotetext{
${ }^{15}$ If borrowers and lenders have different marginal propensities to consume then a shift in resourses from one group to the other would result in either a rise or a fall in aggregate consumption. However in this model we abstract from that possibility and assume that all excess profits are returned to the household as dividends and that the household is the only agent that consumes.
} 
The reasoning is as follows. Following a shock that results in an increase in economic activity, asset prices will rise. This leads to an increase in entrepreneur net worth and an improvement in their balance sheets. This alone should reduce the riskiness of lending to the entrepreneurial sector. If there is a positive co-movement between $G D P$ and inflation then the shock which boosts GDP will also lead to unanticipated inflation. When debt contracts are written in nominal terms, this will reduce the real value of debt on entrepreneur balance sheets, leading to a further increase in real net worth and a further reduction in risk. Thus the "Fisher debt-deflation channel" strengthens the feedback loop that occurs after a shock that leads to a positive co-movement between GDP and inflation in a model with financial frictions.

If there is a negative co-movement between GDP and inflation then the shock which boosts $G D P$ will lead to unanticipated deflation. This causes the real value of debt to increase and worsens an entrepreneur's balance sheet. So while the boost to GDP leads to an increase in asset prices and improved balance sheets, the unanticipated deflation and the increase in the real value of debt has the opposite effect. Thus the Fisher debt-deflation channel will weaken any feedback loop that occurs after a shock that produces a negative co-movement between GDP and inflation.

Table 5 presents GDP volatility, as calculated from simulations of the model, under the assumption of indexed or non-indexed debt contracts. The top half of the table presents the results for simulations of the model where business cycles are driven by monetary policy shocks and the bottom half presents the results from the model with productivity shocks. The table also presents results from simulations of the model where wages are sticky (and thus $\xi_{w}>0$ ) or where wages are perfectly flexible $\left(\xi_{w}=0\right)$.

The table shows that bond indexation doesn't matter in the version of the model with no financial accelerator. Just as the earlier intuition would predict, when there is a financial accelerator and business cycles are driven by monetary shocks, the positive co-movement between inflation and $G D P$ implies that the feedback loop associated with the financial accelerator is stronger and results in more volatile business cycle fluctuations when debt contracts are not indexed. The bottom half of the table shows that the exact opposite is true in a model with productivity shocks when there is a negative co-movement between GDP and inflation. In this case, the business cycle volatility is lower when debt contracts are nominal terms.

Under the benchmark parameterization, with non-indexed debt contracts and sticky wages, 
the introduction of financial frictions in both the entrepreneurial and banking sectors leads to an $18-20 \%$ increase in GDP in the model with monetary policy shocks. When wages are sticky but debt contracts are indexed, the same financial accelerator mechanisms lead to a $15-17 \%$ increase in $G D P$ volatility. The qualitative effect of the financial accelerator is exactly as we would expect from the theory. However, quantitatively, the effect is not very strong.

The reason that debt-indexation is qualitatively, but not quantitatively important is because under both wage and price rigidity, prices are sluggish. The non-indexation of debt and the Fisher debt-deflation channel works only because of inflation surprises. When inflation is sluggish, inflation surprises are not as quantitatively important, so the Fisher debt-deflation channel is not as quantitatively important.

The table also presents the results from a version of the model with perfectly flexible wages. In this case, when debt-contracts are non-indexed, including the financial accelerator mechanism in both the entrepreneurial and banking sectors leads to a $20-26 \%$ increase in $G D P$ volatility. When debt contracts are indexed, and thus the Fisher debt-deflation channel is not active, the financial accelerator mechanisms lead to a $13-15 \%$ increase in GDP volatility. Thus when wages are perfectly flexible, and thus inflation is less sluggish and surprises are more likely, the Fisher debtdeflation channel accounts for almost half of the strength of the financial accelerator mechanism.

\subsubsection{The effect of a firm's access to short term working capital}

In the model, firms must pay their wage bill in advance and borrow working capital from banks. Thus banks are not only responsible for making long term physical capital loans to entrepreneurs, they provide short term financing to firms.

Conventional financial accelerator models with frictions only in the entrepreneurial sector would not capture the channel whereby financial frictions lead to a shortage of short term working capital financing. In this model, since there is no risk among firms, banks charge an interest rate for working capital loans equal to their own cost of capital, $r_{t}^{w c}=r_{t}^{b}$. Thus a disruption in the banking sector that leads to an increase in the bank's cost of capital is immediately passed on to firms in the form of higher priced short term financing.

Of course at the same time, an increase in the banks cost of capital is also passed on to entrepreneurs in the form of higher rates on long term physical capital loans. By changing the 
model and assuming that firms obtain their short term working capital financing directly from households at the risk free rate of interest, $r_{t}^{w c}=i_{t}$, we can separate these two channels. ${ }^{16}$

The results from the model under these two alternate assumptions, that problems in the banking sector can affect a firm's access to short term working capital (WC), or that firms borrow working capital at the risk free rate and thus access to working capital financing is immune to problems in the banking sector (No WC) are presented in table 6 .

There is no difference between the WC and No WC lines in the table in the versions of the model without financial frictions in the banking sector. However in the version of the model with frictions in the banking sector but where firms borrow working capital at the risk free rate, frictions in the banking sector lead to about a $5-6 \%$ increase in $G D P$ volatility in the model driven by monetary shocks and a $1 \%$ increase in volatility under productivity shocks. This is similar in magnitude to the effect of introducing the financial accelerator in the entrepreneurial sector.

In the benchmark version of the model, when firms borrow working capital at the interbank rate, the introduction of frictions in the banking sector leads to a $10-12 \%$ increase in $G D P$ volatility under monetary policy shocks and a $3 \%$ increase under productivity shocks. Thus separating the effect of banking frictions on long term lending to the entrepreneurial sector from short term lending to firms shows that financial frictions are introduced in the banking sector, about one-half of the increased GDP volatility is due to the disruption in long term financing and the other half is due to the disruption in short term financing.

\subsubsection{The effect of a bank's capital cushion}

As highlighted by the recent financial crisis, the size of a bank's capital cushion affects its ability to absorb loan losses. The model is calibrated such that the steady state debt-asset ratio for banks is equal to $90 \%$. However during the recent financial crisis, some (in)famous financial institutions were leveraged more than 30 times, meaning that their debt-asset ratio was around $97 \%$.

The results from simulations of the model assuming different steady state debt-asset ratios for

\footnotetext{
${ }^{16}$ Ohanian (2010) argues that the 2007-2009 crisis in the United States was marked by a significant increase in the wedge between the marginal product of labor and the marginal utility of substitution between consumption and leisure. He goes on to argue that conventional models with financial frictions cannot account for this fact since in most models financial frictions primarily affect the market for physical capital. In this model, the interest rate on working capital loans provides a wedge between the marginal product of labor and the marginal disutility of labor, and thus this model with frictions in the banking sector can explain why the labor wedge grew in the recent crisis.
} 
banks is presented in table 7 . The table presents the results from simulations of the model where banks have a $30 \%$ capital asset ratio (and thus the leverage ratio is 2.33 ) a $10 \%$ capital-asset ratio (and thus the leverage ratio is 9 ) and a 3\% capital-asset ratio (and thus the leverage ratio is about

32.3). It is important to note that across these three simulations of the model, the steady state risk in the banking sector is held constant. Thus in all three versions of the model there is a 13 basis point spread between the interbank rate and the risk free rate in the steady state. Apart from the steady state debt-asset ratio in the banking sector, the steady state variables of the model do not change between the three alternate parameterizations in table 7. Thus the level of risk doesn't change, only a bank's capacity to absorb that risk.

In the versions of the model with no financial frictions in the banking sector, varying a bank's leverage has no effect. This is simply the Miller and Modigliani theorem. When there are frictions in the financial sector, holding constant the level of risk in the banking sector, the size of a bank's capital cushion has a major effect on the power of financial frictions in the banking sector as an amplification mechanism. Recall in the benchmark parameterization when the steady state debtasset ratio is $10 \%$, introducing frictions in the banking sector leads to a $10-12 \%$ increase in GDP volatility under monetary shocks and a 3\% increase in volatility under productivity shocks. When the steady state debt-asset ratio is $30 \%$, the marginal effect of adding frictions in the banking sector is about $7 \%$ in a model with monetary shocks and about $2 \%$ under productivity shocks.

Thus holding fixed the riskiness of the banking sector, frictions in the banking sector are less important as an amplification mechanism when bank's have large capital cushions with which to absorb losses. On the other side, when the steady state debt-asset ratio in the bank sector is $97 \%$, introducing financial frictions in the banking sector increases GDP volatility by $18-21 \%$ under monetary shocks and about $5 \%$ under productivity shocks. Thus reducing the size of banks' capital cushions from $10 \%$ of assets to $3 \%$ leads to a near doubling of the amplification mechanism that arises because of financial frictions in the banking sector.

\subsection{Shocks arising in the financial sector}

The model in this paper gives rise to new type of macroeconomic shock, a shock to risk in the banking system. In the model, this is done by making $\sigma_{t}^{b}$, the parameter describing the uninsurable ex-ante uncertainty about the health of a particular bank's assets, a stochastic process. As can be 
seen from the expression for the interbank lending spread in (15), a shock to $\sigma_{t}^{b}$ will lead to higher interbank lending spreads for a given value of $\bar{\omega}_{t}^{b}$. Another way to think about shocks to $\sigma_{t}^{b}$ is that they are changes to the interbank spread that are orthogonal to the real factors that affect a bank's balance sheet.

Gilchrist et al. (2009), Bordo and Haubrich (2010), Helbling et al. (2010), and Claessens et al. (2010) empirically document the role of shocks in the intermediation process itself. Within the framework of a financial accelerator model, a number of recent papers, like Attah-Mensah and Dib (2008), Christiano et al. (2008), Nolan and Thoenissen (2009), Jermann and Quadrini (2009), and Gilchrist et al. (2009) have introduced credit shocks into a DSGE model.

A shock to $\sigma_{t}^{b}$, a sudden increase in uncertainty in the financial sector, can come about for a number of reasons. There can be the sudden realization that assets once considered safe suddenly aren't, or a disruption caused when off-balance sheet items are moved back on to the balance sheet. In terms of the model, a shock to $\sigma_{t}^{b}$ simply causes an increase in interbank lending rates for a given set of real variables that might affect a bank's default risk. Therefore in terms of the model, a shock to $\sigma_{t}^{b}$ can also be thought of as a sudden increase in risk aversion.

The opaque nature of these shocks to $\sigma_{t}^{b}$ means that they cannot be easily estimated like a TFP shock which is simply estimated from a series of Solow residuals. Therefore to examine the effect of these shocks to financial sector uncertainty we will simply assume that $\sigma_{t}^{b}$ follows an $\mathrm{AR}(1)$ process with autoregressive parameter $\rho$ :

$$
\sigma_{t+1}^{b}=\rho \sigma_{t}^{b}+\left(\sqrt{1-\rho^{2}}\right) \varepsilon_{t}
$$

where $\varepsilon_{t}$ is an i.i.d. disturbance with mean 0 and variance 1 . The coefficient of $\varepsilon_{t}, \sqrt{1-\rho^{2}}$, is included to ensure that the variance of $\sigma_{t}^{b}$ is held constant as we change the autoregressive parameter $\rho$.

Figure 6 presents the responses of the relative price of capital, $\sigma_{t}^{b}$, and lending spreads in a closed economy to a $1 \%$ innovation in $\varepsilon_{t}$. The results are presented from simulations of the model under three different values of $\rho$. The model is calculated when $\rho=.9$ (Persistent), when $\rho=.5$ (Moderate), and when $\rho=.1$ (Transitory).

The responses of the relative price of capital and the lending spreads show that the shock to 
$\sigma_{t}^{b}$ has very little effect when the shock is only transitory but a large effect when the shock is persistent. This is even after multiplying the $1 \%$ innovation by $\sqrt{1-\rho^{2}}$. This correction implies that the variance of $\sigma_{t}^{b}$ is the same regardless of whether the shock is transitory or persistent, but we still see that shocks to financial sector risk have very little effect on asset prices or lending spreads when the shock is transitory.

Figure 5 shows the response of $G D P$ inflation, investment and consumption following the same shock to risk in the financial sector. He again we can see that the macroeconomic effect of a financial sector risk shock is very dependent on its persistence. When the shock is transitory $(\rho=.1), G D P$ falls by about $0.1 \%$ and investment falls by about $0.5 \%$. When the shock is persistent $(\rho=.9)$, GDP falls by $1 \%$ and investment falls by $6 \%$.

The volatility and co-movement of $G D P$ and other macroeconomic variables in a model where business cycles are driven by financial sector risk shocks are presented in table 8 . The table presents results from the versions of the model with a closed economy, two large open economies, and a small open economy. In the table the results are presented for simulations of the model assuming that shocks to financial sector risk assuming $\rho=0.9, \rho=0.5$, or $\rho=0.1$.

The table shows that when business cycles are driven by persistent financial shocks, the resultant $G D P$ volatility is about twenty times higher than when they are driven by transitory financial shocks. This is true even though the variance of the underlying financial shock, $\sigma_{t}^{b}$, is held constant as the persistence of the process changes. Notice as well that when the financial shocks are persistent, inflation and output are highly negatively correlated, the correlation is about -0.75 . However as the persistence of the financial shock decreases, the correlation between inflation and co-movement increases. The correlation is about -0.3 for the simulations where the financial shocks are transitory or have only moderate persistence. If demand shocks are marked by a highly positive correlation between inflation and output and supply shocks are distinguished by a highly negative correlation, then a very persistent financial shock behave very much like a supply shock, but a more transitory financial shock behaves less like a supply shock and more like a mix of the two. 


\section{Conclusion}

This paper presents a simple and highly tractable model with financial frictions in both the real and financial sectors.

As discussed in the introduction, the model is at its heart a new Keynesian model. The model simply adds two financial frictions in the form of non-insurable idiosyncratic draws $\omega_{t}^{e}(j)$ and $\omega_{t}^{b}(k)$. These draws introduce heterogeneity among entrepreneurs and banks. These non-insurablility introduces the financial frictions, in the form of incomplete markets, necessary to overcome the implications of the Miller and Modigliani theorem.

The variables introducing financial frictions, $\omega_{t}^{e}(j)$ and $\omega_{t}^{b}(k)$, are drawn from independent distributions, but the two financial frictions are linked through a bank's balance sheet. The friction in the entrepreneurial sector gives rise to defaults in the entrepreneurial sector and losses on physical capital loans. Due to heterogeneity in a bank's exposure to the set of bad loans, increased defaults in the real sector of the economy lead to increased uncertainty in the financial sector. The model gives rise two separate feedback loops where the an initial shock is propagated through its effect on entrepreneur, and ultimately bank balance sheets.

The combination of these two frictions can explain the finding that when a recession is accompanied by a financial crisis, it tends to be more severe and the recovery slower than ordinary recession. This paper presents a positive analysis. The normative question of how should policy, particularly monetary policy, react to these financial frictions and the possibility of an adverse feedback loop is the obvious direction for further research.

The Taylor rule parameters in this paper were simply set to values commonly found in the literature. Knowing that financial frictions leave open the possibility of a feedback loop, should the central bank place a greater weight on the output gap? Knowing that surprise inflation can reduce the real value of debt and thus lessen pressure on squeezed balance sheets, might the central bank be willing to tolerate more inflation? Similarly, should the central bank include financial variables, like interest rate spreads, in the policy rule? 


\section{References}

Adrian, Tobias, and Hyun Song Shin, 2008, Financial intermediaries, financial stability, and monetary policy, Federal Reserve Bank of New York Staff Reports, No. 346.

Adrian, Tobias, Emanuel Moench, and Hyun Song Shin, 2010a, Financial intermediation, asset prices, and macroieconomic dynamics, Federal Reserve Bank of New York Staff Reports, No. 422.

2010b, Macro risk premium and intermediary balance shhet quantities, Federal Reserve Bank of New York Staff Reports, No. 428.

Aikman, David, and Matthais Paustain, 2006, Bank capital, asset prices, and monetary policy, Bank of England Working Paper No. 305.

Atta-Mensah, Joseph, and Ali Dib, 2008, Bank lending, credit shocks, and the transmission of canadian monetary policy, International Reveiw of Economics and Finance 17(1), 159-176.

Bean, Charles, 2009, The great moderation, the great panic, and the great contraction, Schumpeter Lecture, Annual Congress of the European Economic Association, Barcelona, 25 August 2009.

Bernanke, Ben S., 1983, Non-monetary effects of the financial crisis in the propagation of the great depression, The American Economic Review 73(3), 257-276.

February 24, 2009, Semiannual monetary policy report to the congress, Before the Committee on Banking, Housing and Urban Affairs, U.S. Senate, Washington, D.C.

Bernanke, Ben S., and Cara S. Lown, 1991, The credit crunch, Brookings Papers on Economic Activity 1991(2), 205-247.

Bernanke, Ben S., and Mark Gertler, 1989, Agency costs, net worth, and business fluctuations, The American Economic Review 79(1), 14-31.

1995, Inside the black box: The credit channel and monetary policy transmission, Journal of Economic Perspectives 9(4), 27-48.

Bernanke, Ben S., Mark Gertler, and Simon Gilchrist, 1999, The financial accelerator in a quantitative business cycle framework, in: John B. Taylor, Michael Woodford, eds, Handbook of Macroeconomicsvol. 1 ) 1341-1393.

Bordo, Michael D., and Joseph G. Haubrich, 2010, Credit crises, money and contractions: An historical view, Journal of Monetary Economics 57, 1-18.

Calvo, Guillermo A., 1983, Staggered prices in a utility-maximizing framework, Journal of Monetary Economics 12, 383-398.

Carlstrom, Charles T., and Timothy S. Fuerst, 1997, Agency costs, net worth, and business fluctuations: A computable general equilibrium analysis, The American Economic Review 87(5), 893910 .

Cecchetti, Stephen D., Marion Kohler, and Christian Upper, 2009, Financial crises and economic activity, NBER Working Paper No. 15379. 
Chari, V.V., Patrick J. Kehoe, and Ellen R. McGrattan, 2002, Can sticky price models generate volatile and persistent real exchange rates, Review of Economic Studies 69(3), 533-563.

Chen, Nan-Kuang, 2001, Bank net-worth, asset prices, and economic activity, Journal of Monetary Economics 48, 415-436.

Christiano, Lawrence J., Martin Eichenbaum, and Charles L. Evans, 2005, Nominal rigities and the dynamic effects of a shock to monetary policy, Journal of Political Economy 113, 1-45.

Christiano, Lawrence, Roberto Motto, and Massimo Rostagno, November 2008, Financial factors in economic fluctuations, mimeo.

Claessens, Stijn, M. Ayhan Kose, and Marco E. Terrones, May 2010, How do business and financial cycles interact?, mimeo.

Curdia, Vasco, and Michael Woodford, 2009, Credit spreads and monetary policy, Federal Reserve Bank of New York Staff Reports, No. 385.

Dedola, Luca, and Giovanni Lombardo, October 2009, Financial frictions, financial integration, and the international propogation of shocks, The Review of Financial Studies.

Devereux, Michael B., and James Yetman, 2010, Leverage constraints and the international transmission of shocks, NBER Working Paper No. 16226.

Dib, Ali, 2010, Banks, credit market frictions, and business cycles, mimeo.

Fisher, Irving, 1933, The debt-deflation theory of great depressions, Econometrica 1(4), 337-357.

Geanakoplos, John, 2009, The leverage cycle, Cowles Foundation Discussion Paper No. 1715.

Gertler, Mark, 1988, Financial structure and aggregate economic activity: An overview, Journal of Money, Credit, and Banking 20(3), 559-588.

Gertler, Mark, and Nobuhiro Kiyotaki, 2010, Financial intermediation and credit policy in business cycle analysis, in: Benjamin M. Friedman, Michael Woodford, eds, Handbook of Monetary Economicsvol. 3 ).

Gertler, Mark, and Peter Karadi, May 2009, A model of unconventional monetary policy, mimeo.

Gilchrist, Simon, Alberto Ortiz, and Egon Zakrajsek, July 2009a, Credit risk and the macroeconomy: Evidence from an estimated dsge model, mimeo.

Gilchrist, Simon, Vladimir Yankov, and Egon Zakrajsek, 2009b, Credit market shocks and economic fluctuations: Evidence from corporate bond and stock markets, Journal of Monetary Economics 56, 471-493.

Helbling, Thomas, Raju Huidron, M. Ayhan Kose, and Christopher Otrok, October 2010, Do credit shocks matter? a global perspective, mimeo.

Hirakata, Naohisa, Nao Sudo, and Kozo Ueda, 2009, Credit conditions of financial intermediaries and entrepreneurs and financial accelerators, mimeo.

2010, Do banking shocks matter for the u.s. economy?, mimeo. 
Holstrom, Bengt, and Jean Tirole, 1997, Financial intermediation, loanable funds, and the real sector, Quarterly Journal of Economics 112(3), 663-691.

Hubbard, R. Glenn, Kenneth N. Kuttner, and Darius N. Palia, 2002, Are there bank effects in borrower's cost of funds? evidence from a matched sample of borrowers and banks, Journal of Business 75(4), 559-581.

Iacoviello, Matteo, 2005, House prices, borrowing constraints, and monetary policy in the business cycle, The American economic Review 95(3), 739-764.

Jermann, Urban, and Vincenzo Quadrini, 2009, Macroeconomic effects of financial shocks, NBER Working Paper no. 15338.

Kashyap, Anil K., and Jeremy C. Stein, 1995, The impact of monetary policy on bank balance sheets, Carnegie-Rochester Conference Series on Public Policy 42, 151-195.

2000, The impact of monetary policy on bank balance sheets, The American Economic Review 90(3), 407-428.

Kiyotaki, Nobuhiro, and John Moore, 1997, Credit cycles, Journal of Political Economy 105(2), 211248.

Lown, Cara, and Donald P. Morgan, 2006, The credit cycle and the business cycle: New findings using the loan officer opinion survey, Journal of Money, Credit, and Banking 38(6), 1575-1597.

Meh, Cesaire A., and Kevin Moran, 2010, The role of bank capital in the propagation of shocks, Journal of Economic Dynamics and Control 34(3), 555-576.

Modigliani, Franco, and Merton H. Miller, 1958, The cost of capital, corporation finance, and the theory of investment, The American Economic Review 48(3), 261-297.

Nolan, Charles, and Christoph Thoenissen, 2009, Financial shocks and the u.s. business cycle, Journal of Monetary Economics 56, 596-604.

Ohanian, Lee E., 2010, The financial crisis from a neoclassical perspective, Journal of Economic Perspectives 24(4), 45-66.

Peek, Joe, and Eric S. Rosengren, 2000, Collateral damage: Effects of the japanese banking crisis on real activity in the united states, The American Economic Review 90(1), 30-45.

Reinhart, Carmen M., and Kenneth S. Rogoff, 2008, Banking crises: An equal opportunity menace, NBER Working Paper No. 14587.

2009, The aftermath of financial crises, NBER Working Paper No. 14656.

Reinhart, Carmen M., and Vincent R. Reinhart, 2006, After the fall, Paper prepared for the symposium sponsored by The Federal Reserve Bank of Kansas City on Macroeconomic Challenges: The Decade Ahead, Jackson Hole, Wyoming, August 26-28, 2010.

Stein, Jeremy C., 1998, An adverse-selection model of bank asset and liability management with implications for the transmission of monetary policy, The RAND Journal of Economics $29(3), 466-486$. 
Taylor, John B., and John C. Williams, 2009, A black swan in the money market, American Economic Journal: Macroeconomics 1(1), 58-83.

The International Monetary Fund April 2009a, From recession to recovery: How soon and how strong?, World Economic Outlook 103-138.

_ October 2009b, What's the damage? medium-term output dynamics after financial crises, World Economic Outlook 121-151.

Ueda, Kozo, 2010, Banking globalization and international business cycles, Federal Reserve Bank of Dallas, Globalization and Monetary Policy Institute Working Paper No. 58.

van denHeuvel, Skander J., 2009, The bank capital channel of monetary policy, mimeo.

vonPeter, Goetz, 2009, Asset prices and banking distress: A macroeconomic approach, Journal of Financial stability 5, 298-319.

Woodford, Michael, 2010, Financial intermediation and macroeconomic analysis, Journal of Economic Perspectives 24(4), 21-44. 


\section{A Technical Appendix}

This appendix will present some of the more technical derivations in the paper related to the nominal rigidities and financial frictions present in the model. The first part of the appendix, section A.1 presents the derivations involved with the Calvo style wage and price equations. The second part of this appendix, section A.2 presents the proofs necessary for aggregation in the presence of financial frictions.

\section{A.1 Nominal Rigidities}

\section{A.1.1 Sticky Wages}

In any given period, household $j$ faces a probability of $1-\xi_{w}$ of being able to reset their wage, otherwise it is reset automatically according to $W_{t}(l)=\pi_{t-1} W_{t-1}(l)$, where $\pi_{t-1}=\frac{P_{t-1}}{P_{t-2}}$.

If household $j$ is allowed to reset their wages in period $t$ they will set a wage to maximize the expected present value of utility from consumption minus the disutility of labor.

$$
E_{t} \sum_{\tau=0}^{\infty} \beta^{\tau}\left(\xi_{w}\right)^{\tau}\left\{\lambda_{t+\tau} \Pi_{t, t+\tau} W_{t}(l) H_{t+\tau}(l)-\psi\left(H_{t+\tau}(l)\right)^{\frac{1+\sigma_{H}}{\sigma_{H}}}\right\}
$$

where $\lambda_{t+\tau}$ is the marginal utility of consumption in period $t+\tau \cdot{ }^{17}$

$$
\Pi_{t, t+\tau}=\left\{\begin{array}{cc}
1 & \text { if } \tau=0 \\
\pi_{t+\tau-1} \Pi_{t, t+\tau-1} & \text { if } \tau>0
\end{array}\right.
$$

The imperfect combination of labor from different households is described in (19). Use this function to derive the demand function for labor from a specific household:

$$
H_{t}(l)=\left(\frac{W_{t}(l)}{W_{t}}\right)^{-\theta} H_{t}
$$

where $W_{t}=\left(\int_{0}^{n} W_{t}(l)^{1-\theta} d l\right)^{\frac{1}{1-\theta}}$ is the average wage across households, and $H_{t}$ is aggregate labor supplied by all households.

\footnotetext{
${ }^{17}$ We assume complete contingent claims markets among households within a country. This implies that the marginal utility of consumption is the same across all households within a country, regardless of their income. Therefore the total utility from the consumption of labor income in any period is simply the country specific marginal utility of comsumption, $\lambda_{t}$, multiplied by the household's labor income, $W_{t}(l) N_{t}(l)$.
} 
Substitute the labor demand function into the maximization problem to express the maximization problem as a function of one choice variable, the wage rate, $W_{t}(l)$ :

$E_{t} \sum_{\tau=0}^{\infty} \beta^{\tau}\left(\xi_{w}\right)^{\tau}\left\{\lambda_{t+\tau} \Pi_{t, t+\tau} W_{t}(l)\left(\frac{\Pi_{t, t+\tau} W_{t}(l)}{W_{t+\tau}}\right)^{-\theta} H_{t+\tau}-\psi\left(\left(\frac{\Pi_{t, t+\tau} W_{t}(l)}{W_{t+\tau}}\right)^{-\theta} H_{t+\tau}\right)^{\frac{1+\sigma_{H}}{\sigma_{H}}}\right\}$

After some rearranging, the first order condition of this problem is:

$$
W_{t}(l)^{\frac{\theta}{\sigma_{N}}+1}=\frac{\theta}{\theta-1} \frac{1+\sigma_{H}}{\sigma_{H}} \psi\left(W_{t}\right)^{\frac{\theta}{\sigma_{H}}} \frac{E_{t} \sum_{\tau=0}^{\infty} \beta^{\tau}\left(\xi_{w}\right)^{\tau}\left(\frac{W_{t+\tau}}{\Pi_{t, t+\tau} W_{t}}\right)^{\frac{\theta}{\sigma_{H}}+\theta}\left(H_{t+\tau}\right)^{\frac{1+\sigma_{H}}{\sigma_{H}}}}{E_{t} \sum_{\tau=0}^{\infty} \beta^{\tau}\left(\xi_{w}\right)^{\tau} \lambda_{t+\tau} \Pi_{t, t+\tau}\left(\frac{W_{t+\tau}}{\Pi_{t, t+\tau} W_{t}}\right)^{\theta} H_{t+\tau}}
$$

If wages are flexible, and thus $\xi_{w}=0$, this expression reduces to:

$$
W_{t}(l)=\frac{\theta}{\theta-1} \frac{\frac{1+\sigma_{H}}{\sigma_{H}} \psi\left(H_{t}\right)^{\frac{1}{\sigma_{H}}}}{\lambda_{t}}
$$

Thus when wages are flexible the wage rate is equal to a mark-up, $\frac{\theta}{(\theta-1)}$, multiplied by the marginal disutility of labor, $\frac{1+\sigma_{H}}{\sigma_{H}} \psi\left(H_{t}\right)^{\frac{1}{\sigma_{H}}}$, divided by the marginal utility of consumption, $\lambda_{t}$.

Write the wage rate for the household that can reset wages in period $t, W_{t}(l)$, as $\tilde{W}_{t}(l)$ to denote it as an optimal wage. Also note that all households that can reset wages in period $t$ will reset to the same wage rate, so $\tilde{W}_{t}(l)=\tilde{W}_{t}$.

All households face a probability of $\left(1-\xi_{w}\right)$ of being able to reset their wages in a given period, so by the law of large numbers $\left(1-\xi_{w}\right)$ of households can reset their wages in a given period. The wages of the other $\xi_{w}$ will automatically reset by the previous periods inflation rate.

So substitute $\tilde{W}_{t}$ into the expression for the average wage rate $W_{t}=\left(\int_{0}^{n} W_{t}(l)^{1-\theta} d l\right)^{\frac{1}{1-\theta}}$, to derive an expression for the evolution of the average wage:

$$
W_{t}=\left(\xi_{w}\left(\Pi_{t-1, t} W_{t-1}\right)^{1-\theta}+\left(1-\xi_{w}\right)\left(\tilde{W}_{t}\right)^{1-\theta}\right)^{\frac{1}{1-\theta}}
$$

\section{A.1.2 Sticky Output Prices}

Domestic Prices In the model, intermediate goods prices are sticky. Intermediate goods firms can set separate domestic and export prices. 
In period $t$, the firm will be able to change it's price in the domestic market with probability $1-\xi_{p}$. If the firm cannot change prices then they are reset automatically according to $P_{t}^{d}(i)=$ $\pi_{t-1} P_{t-1}^{d}(i)$.

The firm that can reset prices in period $t$ will choose $P_{t}^{d}(i)$ to maximize discounted future profits:

$$
\max _{P_{t}^{d}(i)} E_{t} \sum_{\tau=0}^{\infty} \beta^{\tau}\left(\xi_{p}\right)^{\tau} \lambda_{t+\tau}\left\{\Pi_{t, t+\tau} P_{t}^{d}(i) y_{t+\tau}^{d}(i)-M C_{t+\tau} y_{t+\tau}^{d}(i)\right\}
$$

where $M C_{t+\tau}$ is marginal cost of production in period $t+\tau$.

The firm's domestic demand is given in (3). Substitute this demand function into the maximization problem to express this problem as a function of one choice variable, $P_{t}(i)$ :

$$
\max _{P_{t}^{d}(i)} E_{t} \sum_{\tau=0}^{\infty} \beta^{\tau}\left(\xi_{p}\right)^{\tau} \lambda_{t+\tau}\left\{\begin{array}{c}
\Pi_{t, t+\tau} P_{t}^{d}(i) \gamma(n)^{\frac{1-\rho}{1-\sigma}-1}\left(\frac{\Pi_{t, t+\tau} P_{t}^{d}(i)}{P_{t+\tau}^{d}}\right)^{-\sigma}\left(\frac{P_{t+\tau}^{d}}{P_{t+\tau}}\right)^{-\rho} y_{t+\tau} \\
-M C_{t+\tau} \gamma(n)^{\frac{1-\rho}{1-\sigma}-1}\left(\frac{\Pi_{t, t+\tau} P_{t}^{d}(i)}{P_{t+\tau}^{d}}\right)^{-\sigma}\left(\frac{P_{t+\tau}^{d}}{P_{t+\tau}}\right)^{-\rho} y_{t+\tau}
\end{array}\right\}
$$

After some rearranging, the first order condition with respect to $P_{t}^{d}(i)$ is:

$$
P_{t}^{d}(i)=\frac{\sigma}{\sigma-1} \frac{E_{t} \sum_{\tau=0}^{\infty} \beta^{\tau}\left(\xi_{p}\right)^{\tau} \lambda_{t+\tau} M C_{t+\tau}\left(\frac{\Pi_{t, t+\tau}}{P_{t+\tau}^{d}}\right)^{-\sigma}\left(\frac{P_{t+\tau}^{d}}{P_{t+\tau}}\right)^{-\rho} y_{t+\tau}}{E_{t} \sum_{\tau=0}^{\infty} \beta^{\tau}\left(\xi_{p}\right)^{\tau} \lambda_{t+\tau} \Pi_{t, t+\tau}\left(\frac{\Pi_{t, t+\tau}}{P_{t+\tau}^{d}}\right)^{-\sigma}\left(\frac{P_{t+\tau}^{d}}{P_{t+\tau}}\right)^{-\rho} y_{t+\tau}}
$$

If prices are flexible, and thus $\xi_{p}=0$, then this expression reduces to:

$$
P_{t}^{d}(i)=\frac{\sigma}{\sigma-1} M C_{t}
$$

which says that the firm will set a price equal to a constant mark-up over marginal cost.

Write the domestic price set by the firm that can reset prices in period $t$ as $\tilde{P}_{t}^{d}(i)$ to denote that it is an optimal price. Firms that can reset prices in period $t$ will all reset to the same level, so $\tilde{P}_{t}^{d}(i)=\tilde{P}_{t}^{d}$. Substitute this optimal price into the price index $P_{t}^{d}=\left(\frac{1}{n} \int_{0}^{n}\left(P_{t}^{d}(i)\right)^{1-\sigma} d i\right)^{\frac{1}{1-\sigma}}$ and use the fact that in any period $1-\xi_{p}$ percent of firms will reoptimize prices, and the prices of $\xi_{p}$ percent of firms will be automatically reset using the previous periods inflation rate, to derive an expression for the domestic price index, $P_{t}^{d}$ : 


$$
P_{t}^{d}=\left(\xi_{p}\left(\Pi_{t-1, t} P_{t-1}^{d}\right)^{1-\sigma}+\left(1-\xi_{p}\right)\left(\tilde{P}_{t}^{d}\right)^{1-\sigma}\right)^{\frac{1}{1-\sigma}}
$$

Export Prices Domestic firm $i$, where $i \in[0, n]$, will set a price $P_{t}^{m *}(i)$ for its intermediate input in the foreign market.

The demand for the intermediate good from domestic firm $i$ in the rest of the world is given by:

$$
y_{t}^{m *}(i)=(n)^{\frac{1-\rho}{1-\sigma}-1}\left(\frac{P_{t}^{m *}(i)}{P_{t}^{m *}}\right)^{-\sigma}\left(\frac{P_{t}^{m *}}{P_{t}^{*}}\right)^{-\rho} y_{t}^{*}
$$

In period $t$, the firm will be able to change it's export price with probability $1-\xi_{p}$. If the firm cannot change its price in the foreign market then it is reset automatically according to $P_{t}^{m *}(i)=\pi_{t-1}^{*} P_{t-1}^{m *}(i)$, where $\pi_{t-1}^{*}=\frac{P_{t-1}^{*}}{P_{t-2}^{*}}$.

If domestic firm $i$ was last able to change their export price in period $t$, the demand for the intermediate good from firm $i$ in the rest of the world in period $t+\tau$ is:

$$
y_{t+\tau}^{m *}(i)=\gamma^{f *}(n)^{\frac{1-\rho}{1-\sigma}-1}\left(\frac{\Pi_{t, t+\tau}^{*} P_{t}^{m *}(i)}{P_{t+\tau}^{m *}}\right)^{-\sigma}\left(\frac{P_{t+\tau}^{m *}}{P_{t+\tau}^{*}}\right)^{-\rho} y_{t+\tau}^{*}
$$

The firm that can reset prices in period $t$ will choose $P_{t}^{m *}(i)$ to maximize discounted future profits:

$$
\max _{P_{t}^{m *}(i)} E_{t} \sum_{\tau=0}^{\infty} \beta^{\tau}\left(\xi_{p}\right)^{\tau} \lambda_{t+\tau}\left\{\Pi_{t, t+\tau}^{*} \frac{P_{t}^{m *}(i)}{S_{t+\tau}} y_{t+\tau}^{m *}(i)-M C_{t+\tau} \frac{y_{t+\tau}^{m *}(i)}{1-c}\right\}
$$

where $S_{t}$ is the nominal exchange rate denoted in units of the foreign currency per units of the home currency.

After some rearranging, the first order condition with respect to $P_{t}^{m *}(i)$ is:

$$
P_{t}^{m *}(i)=\frac{\sigma}{\sigma-1} \frac{E_{t} \sum_{\tau=0}^{\infty} \beta^{\tau}\left(\xi_{p}\right)^{\tau} \lambda_{t+\tau} \frac{M C_{t+\tau}}{1-c}\left(\frac{\Pi_{t, t+\tau}^{*}}{P_{t+\tau}^{m *}}\right)^{-\sigma}\left(\frac{P_{t+\tau}^{m *}}{P_{t+\tau}^{*}}\right)^{-\rho} y_{t+\tau}^{*}}{E_{t} \sum_{\tau=0}^{\infty} \beta^{\tau}\left(\xi_{p}\right)^{\tau} \lambda_{t+\tau} \frac{\Pi_{t, t+\tau}^{*}}{S_{t+\tau}}\left(\frac{\Pi_{t, t+\tau}^{*}}{P_{t+\tau}^{m *}}\right)^{-\sigma}\left(\frac{P_{t+\tau}^{m *}}{P_{t+\tau}^{*}}\right)^{-\rho} y_{t+\tau}^{*}}
$$

If prices are flexible, and thus $\xi_{p}=0$, then this expression reduces to:

$$
P_{t}^{m *}(i)=\frac{\sigma}{\sigma-1} \frac{S_{t} M C_{t}}{1-c}
$$


Denote $\tilde{P}_{t}^{m *}(i)$ as the optimal price for the foreign market set by a firm that was able to change their prices in period $t$. Firms that can reset prices in period $t$ will all reset to the same level, so $\tilde{P}_{t}^{m *}(i)=\tilde{P}_{t}^{m *}$. Substitute this optimal price into the price index $P_{t}^{m *}=\left(\frac{1}{n} \int_{0}^{n}\left(P_{t}^{m *}(i)\right)^{1-\sigma} d i\right)^{\frac{1}{1-\sigma}}$ and use the fact that in any period $1-\xi_{p}$ percent of firms will reoptimize prices, and the prices of $\xi_{p}$ percent of firms will be automatically reset using the previous periods inflation rate, to derive an expression for the import price index, $P_{t}^{m *}$ :

$$
P_{t}^{m *}=\left(\xi_{p}\left(\Pi_{t-1, t}^{*} P_{t-1}^{m *}\right)^{1-\sigma}+\left(1-\xi_{p}\right)\left(\tilde{P}_{t}^{m *}\right)^{1-\sigma}\right)^{\frac{1}{1-\sigma}}
$$

\section{A.2 Financial Frictions}

The derivation of the various interest rates in the model, $r_{t}^{e}, r_{t}^{b}, r_{t}^{w c}$ is presented in the text. However in the text, aggregation was only possible because at the beginning of the period, entrepreneur $j$ 's debt-asset ratio, $D A_{t}^{e}(j)=\frac{b_{t}^{e}(j)}{K_{t}(j)}$, was equal across all entrepreneurs, and bank $k$ 's debt-asset ratio, $D A_{t}^{b}(k)=\frac{b_{t}^{s}(k)+b_{t}^{s f}(k)}{B_{t}^{e}(k)}$, was equal across all banks. This section of the appendix will present the formal proof to both of these claims.

\section{A.2.1 Entrepreneurial sector}

Prove: $D A_{t+1}^{e}(i)=D A_{t+1}^{e}(j)$ :

Entrepreneur $i$ will purchase capital up to the point where:

$$
1+r_{t+1}^{e}(i)=E_{t}\left(\frac{R_{t+1}+\omega_{t+1}^{e}(i) P_{t+1}^{K}(1-\delta) K_{t+1}}{P_{t}^{K}}\right)
$$

Since $E_{t}\left(\omega_{t+1}^{e}(i)\right)=1$ and $\operatorname{cov}\left(\omega_{t+1}^{e}(i), P_{t+1}^{K}(1-\delta) K_{t+1}\right)=0, E_{t}\left(\frac{R_{t+1}+\omega_{t+1}^{e}(i) P_{t+1}^{K}(1-\delta) K_{t+1}}{P_{t}^{K}}\right)=$ $E_{t}\left(\frac{R_{t+1}+P_{t+1}^{K}(1-\delta) K_{t+1}}{P_{t}^{K}}\right)$

Since $E_{t}\left(\frac{R_{t+1}+P_{t+1}^{K}(1-\delta) K_{t+1}}{P_{t}^{K}}\right)$ does not depend on any characteristics that are specific to entrepreneur $i$, in equilibrium $r_{t+1}^{e}(i)=r_{t+1}^{e}(j)$ for any two entrepreneurs $i$ and $j$.

Proof by contradiction:

Suppose $D A_{t+1}^{e}(i)<D A_{t+1}^{e}(j)$

From the bank's optimal loan supply schedule: 
$1+r_{t+1}^{e}(j)=\frac{\left(1+r_{t+1}^{b}\right)}{1-F\left(\bar{\omega}_{t+1}^{e}(j)\right)}-\frac{\left(1-\mu^{e}\right)\left[R_{t+1} F\left(\bar{\omega}_{t+1}^{e}(j)\right)+(1-\delta) P_{t}^{K} \int_{0}^{\bar{\omega}_{t+1}^{e}(j)} \omega_{t+1}^{e} d F\left(\omega_{t+1}^{e}\right)\right]}{\left(1-F\left(\bar{\omega}_{t+1}^{e}(j)\right)\right) \frac{b_{t+1}^{e}(j)}{K_{t+1}(j)}}$

where

$$
\bar{\omega}_{t+1}^{e}(j)=\frac{\left(1+r_{t+1}^{e}\right) \frac{b_{t+1}^{e}(j)}{K_{t+1}(j)}-R_{t+1}}{P_{t+1}^{K}(1-\delta)}
$$

If $D A_{t+1}^{e}(i)<D A_{t+1}^{e}(j)$, then $\frac{b_{t}^{e}(i)}{K_{t}(i)}<\frac{b_{t}^{e}(j)}{K_{t}(j)}$, so $\bar{\omega}_{t}^{e}(i)<\bar{\omega}_{t}^{e}(j)$ and $r_{t}^{e}(i)<r_{t}^{e}(j)$.

This contradicts with the earlier equilibrium condition that $r_{t+1}^{e}(i)=r_{t+1}^{e}(j)$, thus $D A_{t+1}^{e}(i) \nless$ $D A_{t+1}^{e}(j)$ and since the choice of $i$ and $j$ where arbitrary the only possible equilibrium is one where $D A_{t+1}^{e}(i)=D A_{t+1}^{e}(j)$.

\section{A.2.2 Banking sector}

Prove $D A_{t+1}^{b}(i)=D A_{t+1}^{b}(j)$ :

Bank $i$ will make loans up to the point where:

$$
1+r_{t+1}^{b}(i)=E_{t}\left(\left(1-\omega_{t+1}^{b}(k) \zeta_{t+1}^{e}\right)\left(1+r_{t+1}^{e}\right) B_{t+1}^{e}(i)\right)
$$

Since $\omega_{t+1}^{b}(i)$ is i.i.d. and $E_{t}\left(\omega_{t+1}^{b}(i)\right)=1, E_{t}\left(\left(1-\omega_{t+1}^{b}(k) \zeta_{t+1}^{e}\right)\left(1+r_{t+1}^{e}\right) B_{t+1}^{e}(i)\right)=$ $E_{t}\left(\left(1-\zeta_{t+1}^{e}\right)\left(1+r_{t+1}^{e}\right) B_{t+1}^{e}(i)\right)$

Thus $r_{t+1}^{b}(i)=r_{t+1}^{b}(j)$ for any two banks $i$ and $j$.

Proof by contradiction:

Suppose $D A_{t+1}^{b}(i)<D A_{t+1}^{b}(j)$

From the equilibrium condition that determines how much credit is extended to a bank:

$$
1+r_{t+1}^{b}(i)=\frac{1+i_{t+1}}{G\left(\bar{\omega}_{t}^{b}\right)}
$$

where 


$$
\bar{\omega}_{t+1}^{b}(i)=\frac{\left(1+r_{t+1}^{e}\right)-\left(1+r_{t+1}^{b}(i)\right) \frac{b_{t+1}^{s}(i)+b_{t+1}^{s f}(i)}{B_{t+1}^{e}(i)}}{\zeta_{t+1}^{e}\left(1+r_{t+1}^{e}\right)}
$$

If $D A_{t+1}^{b}(i)<D A_{t+1}^{b}(j)$ then $\frac{b_{t+1}^{s}(i)+b_{t+1}^{s f}(i)}{B_{t+1}^{e}(i)}<\frac{b_{t+1}^{s}(j)+b_{t+1}^{s f}(j)}{B_{t+1}^{e}(j)}$, so $\bar{\omega}_{t+1}^{b}(i)>\bar{\omega}_{t+1}^{b}(j)$, so $r_{t+1}^{b}(i)<$ $r_{t+1}^{b}(j)$.

This contradicts with the earlier equilibrium condition that $r_{t+1}^{b}(i)=r_{t+1}^{b}(j)$, thus $D A_{t+1}^{b}(i) \nless$ $D A_{t+1}^{b}(j)$ and since the choice of $i$ and $j$ where arbitrary the only possible equilibrium is one where $D A_{t+1}^{b}(i)=D A_{t+1}^{b}(j)$. 
Table 1: Benchmark Parameter Values

\begin{tabular}{ccl}
\hline \hline Symbol & Value & Description \\
$\beta$ & 0.99 & discount factor \\
$\delta$ & 0.025 & depreciation rate \\
$\alpha$ & 0.36 & capital's share of income \\
$\rho$ & 1.5 & substitution elasticity between home and foreign goods \\
$\chi^{b}$ & 0.01 & cost of adjusting foreign bond holdings \\
$\sigma_{n}$ & 1 & labor supply elasticity \\
$\sigma$ & 10 & substitution elasticity across goods from domestic firms \\
$\theta$ & 21 & substitution elasticity across differentiated labor inputs \\
$\kappa$ & 0.375 & capital adjustment cost parameter \\
$\xi_{p}$ & 0.62 & probability that a firm cannot change prices in the current period \\
$\xi_{w}$ & 0.75 & probability that a worker cannot change wages in the current period \\
$\theta_{i}$ & 0.9 & interest rate smoothing parameter \\
$\theta_{p}$ & 1.5 & weight on inflation in the Taylor rule \\
$\theta_{y}$ & 0.5 & weight on the output gap in the Taylor rule \\
$\gamma$ & $1 ; 0.78 ; 1.42$ & weight on domestic goods (closed economy,large open, small open) \\
$\gamma^{f}$ & $0 ; 0.26 ; 0.25$ & weight on imported goods (closed economy,large open, small open) \\
$\phi$ & 0.271 & fixed cost in production \\
$\psi$ & 0.021 & coefficient on labor effort in the utility function \\
$\sigma^{b}$ & 1.133 & standard deviation of idiosyncratic bank shocks \\
$\mu^{e}$ & 0.134 & cost of liquidation in the entrepreneurial sector \\
$\sigma^{e}$ & 0.370 & standard deviation of idiosyncratic entrepreneur shocks \\
\hline
\end{tabular}

Table 2: Shock Processes used in the simulation

TFP Shocks:

Large open economies

$\boldsymbol{\rho}^{A}=\left[\begin{array}{ll}0.681 & 0.043 \\ 0.043 & 0.681\end{array}\right]$

Closed and Small Economy

$\boldsymbol{\Omega}^{A}=10^{-5}\left[\begin{array}{cc}2.368 & -0.489 \\ -0.489 & 2.368\end{array}\right] \quad \boldsymbol{\Omega}^{A}=10^{-5}\left[\begin{array}{cc}1.658 & 0.039 \\ 0.039 & 1.695\end{array}\right]$

Monetary Policy Shocks:

Large open economies

$\boldsymbol{\rho}^{M}=\left[\begin{array}{ll}0.013 & 0.015 \\ 0.015 & 0.013\end{array}\right]$

$\boldsymbol{\Omega}^{M}=10^{-5}\left[\begin{array}{ll}1.141 & 0.592 \\ 0.592 & 1.141\end{array}\right] \quad \boldsymbol{\Omega}^{M}=10^{-5}\left[\begin{array}{ll}4.282 & 0.292 \\ 0.292 & 2.067\end{array}\right]$

Closed and Small Economy

$\boldsymbol{\rho}^{M}=\left[\begin{array}{cc}-0.001 & 0.004 \\ 0 & 0.015\end{array}\right]$ 


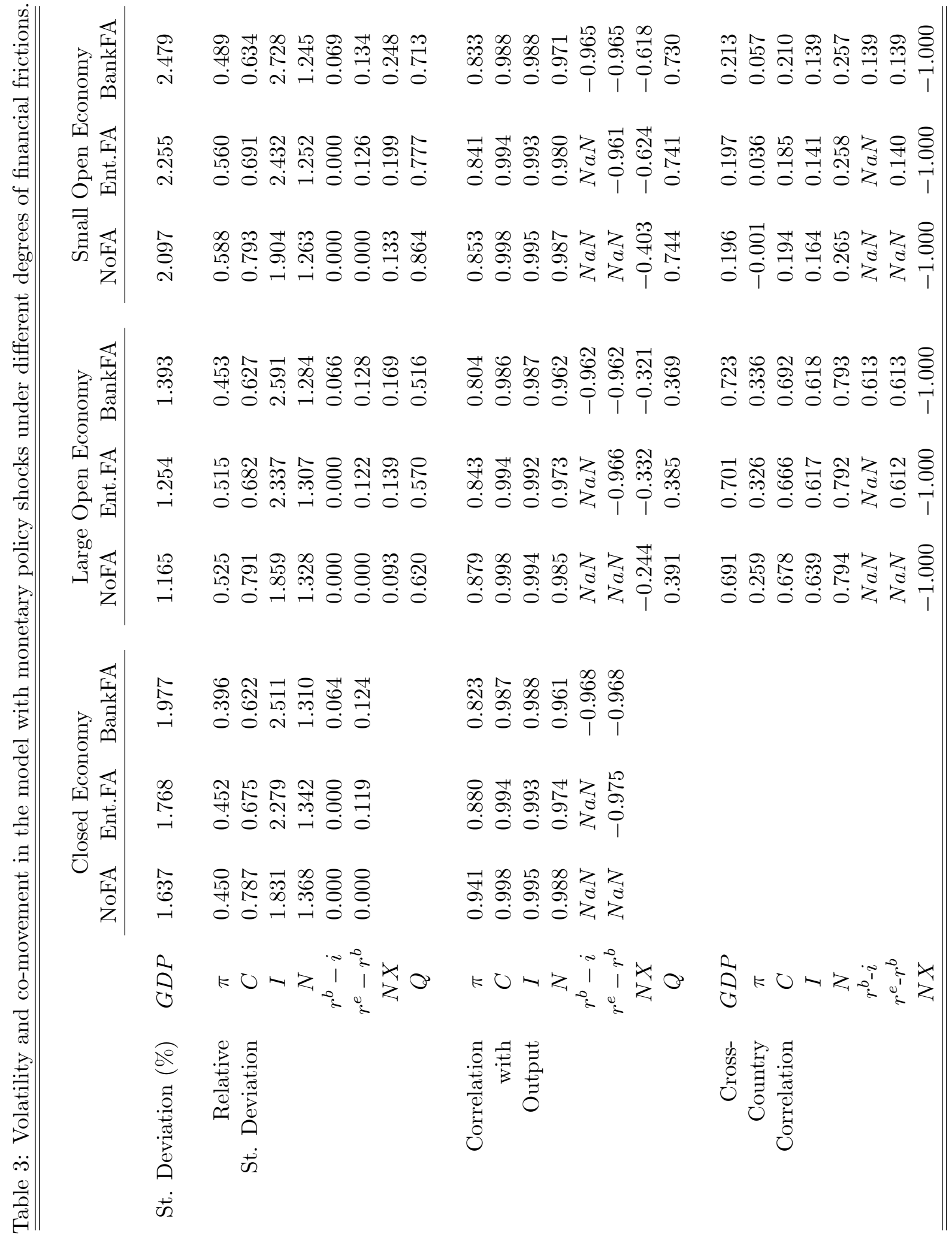




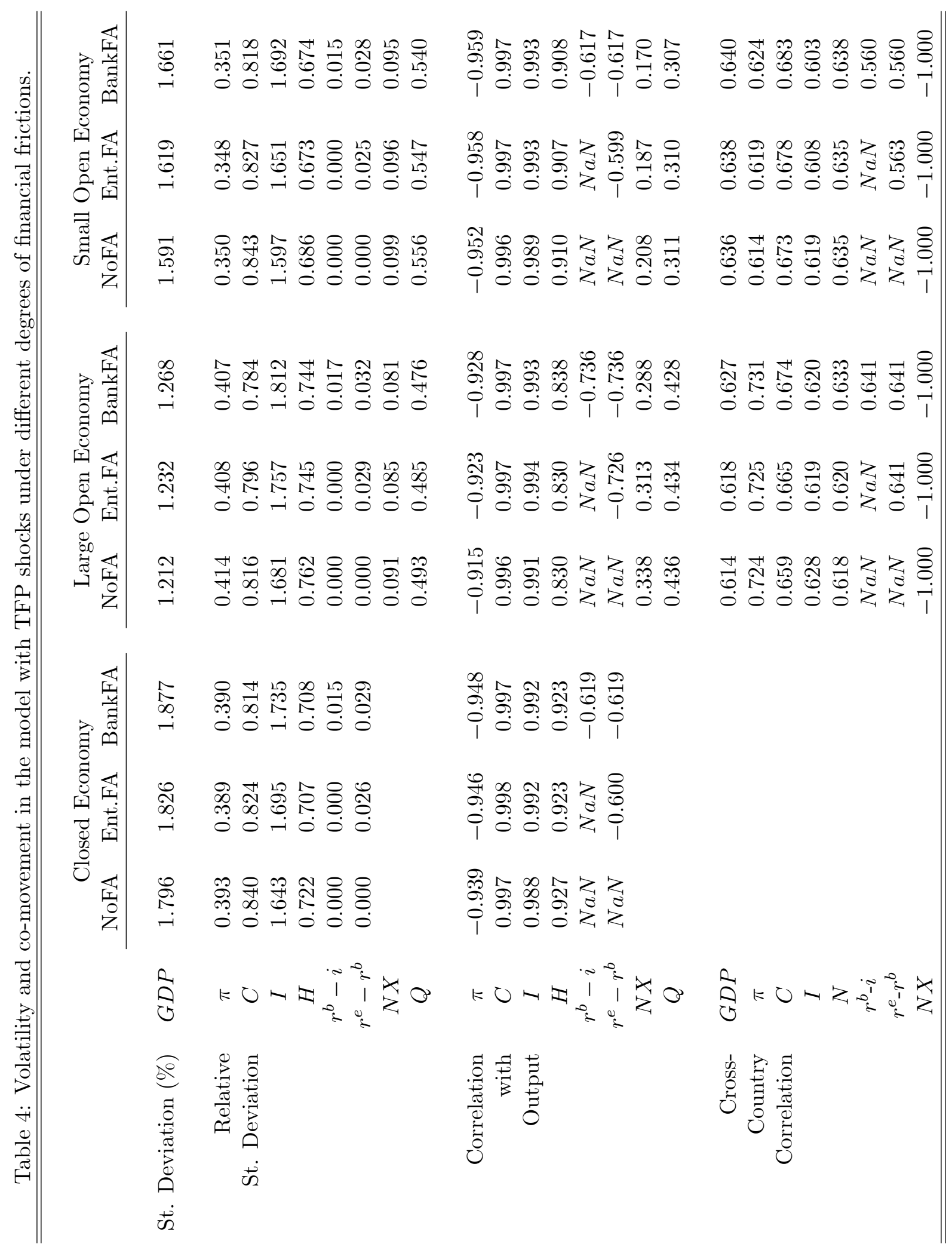




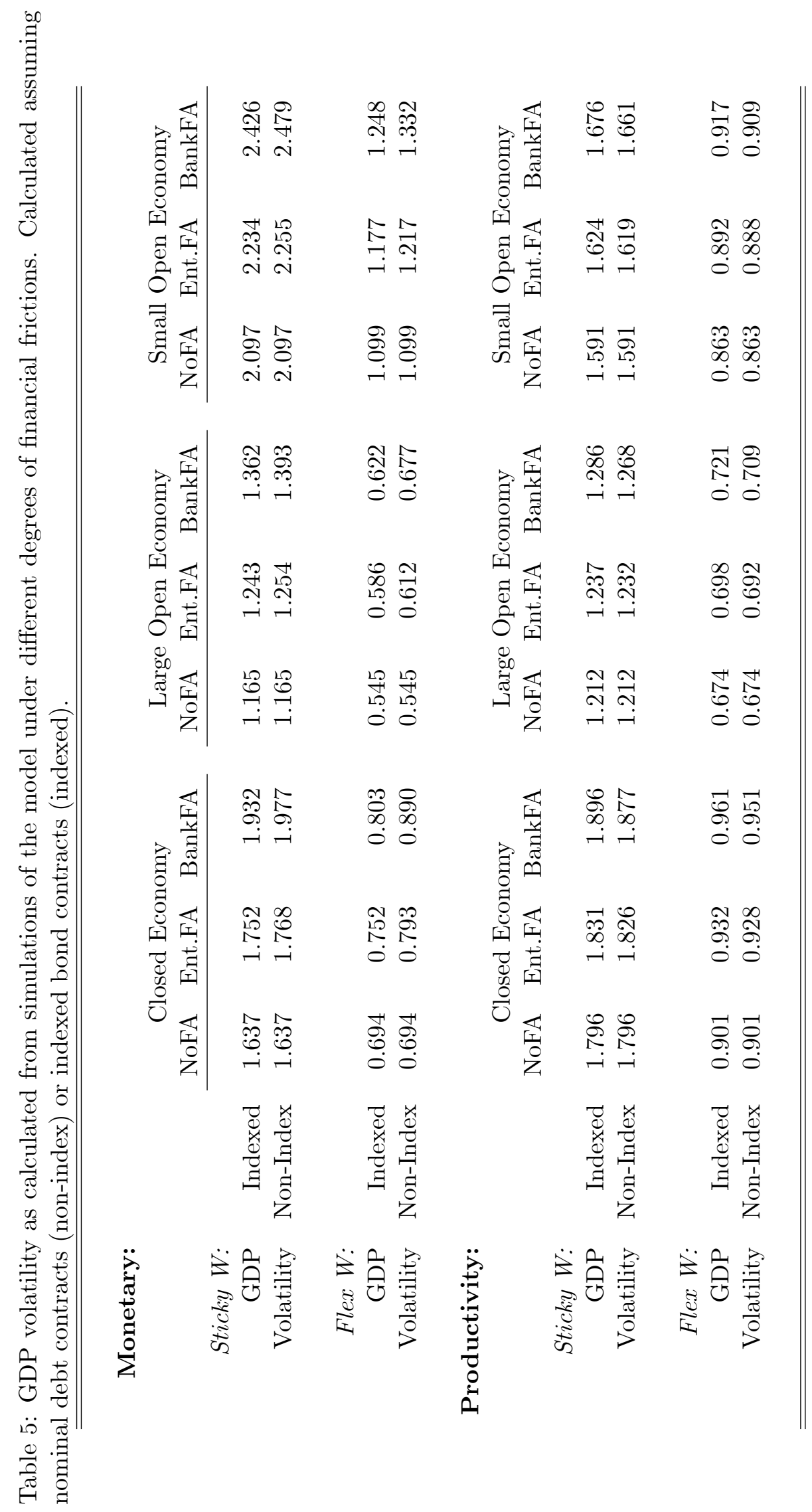




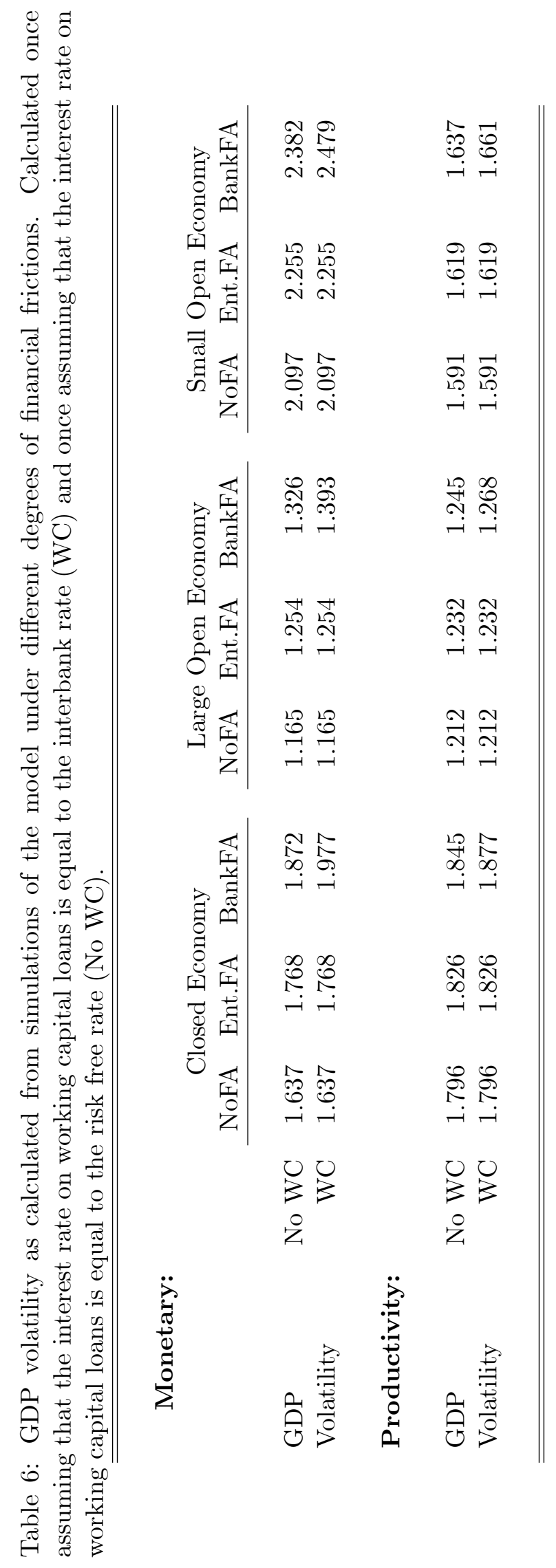




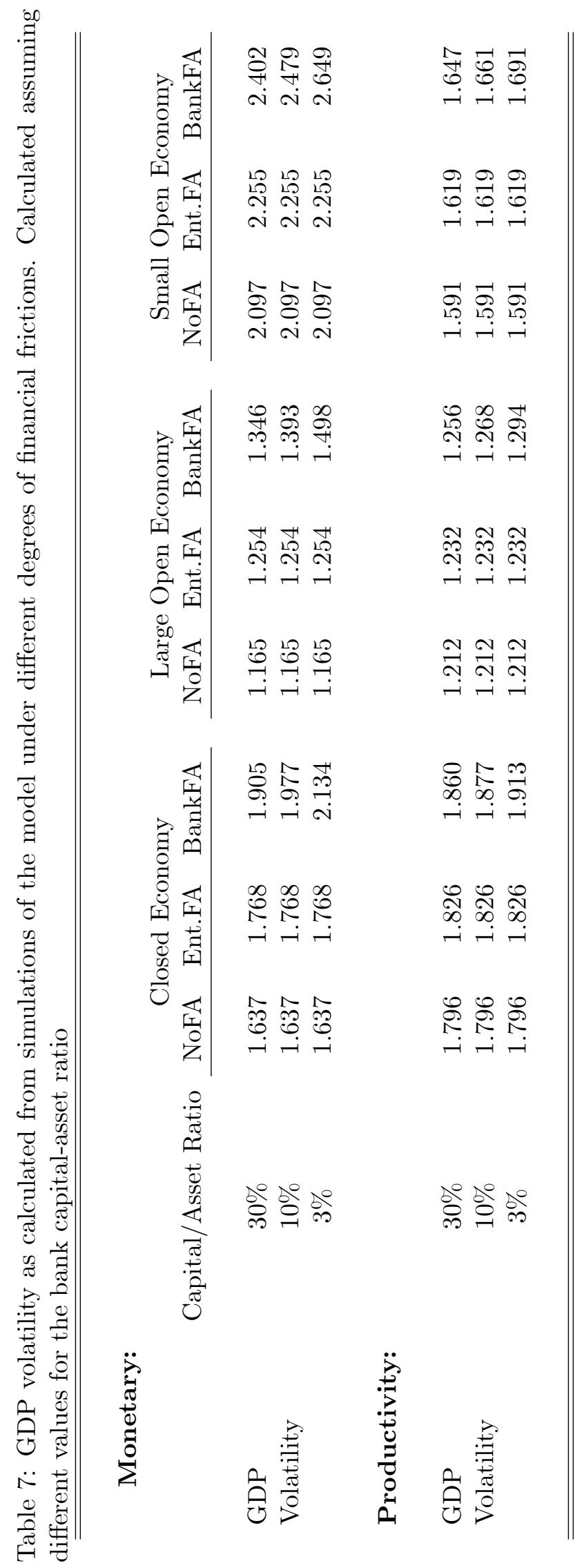




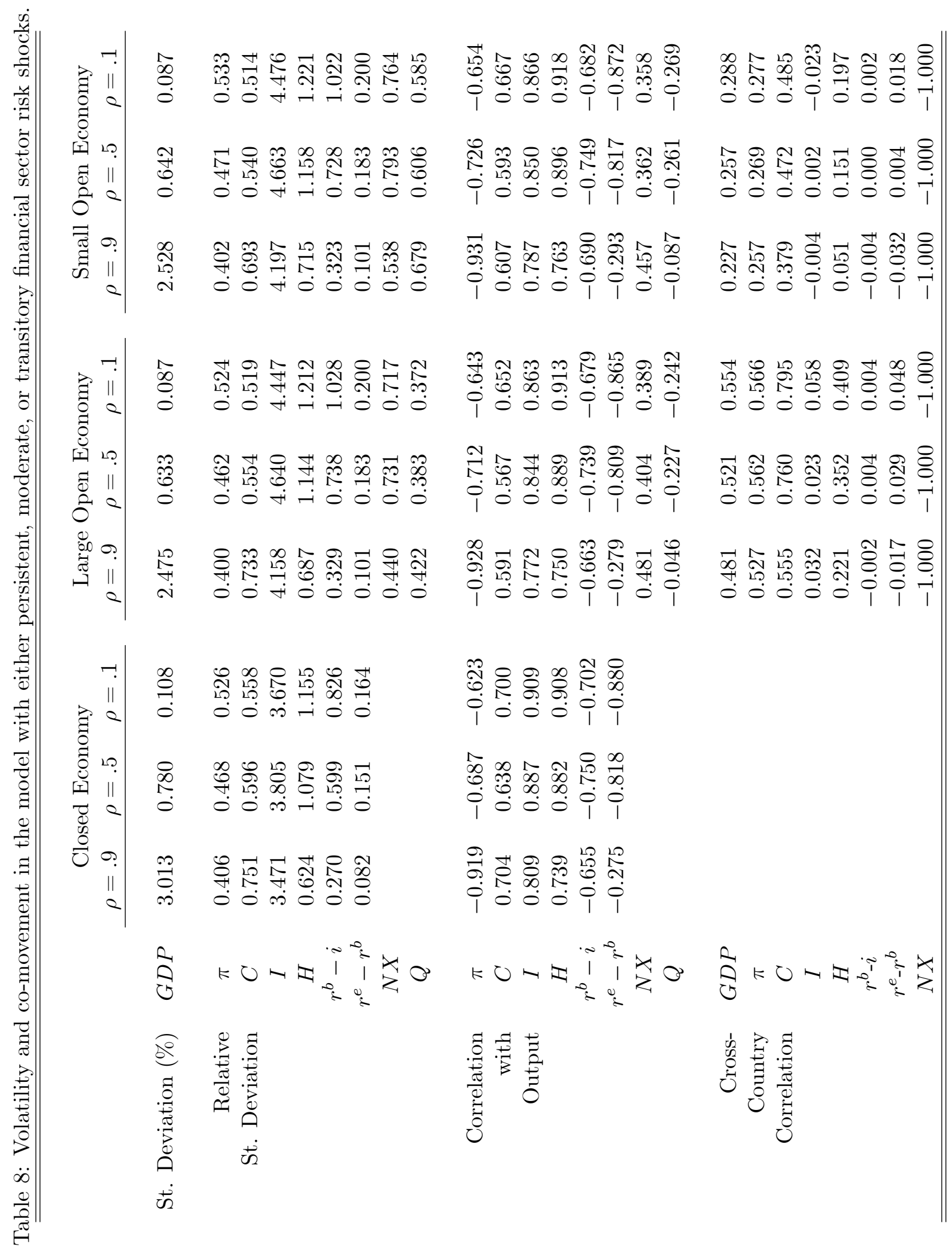


Figure 1: Responses of asset prices, debt-asset ratios, and lending spreads to a monetary policy shock in a closed economy.
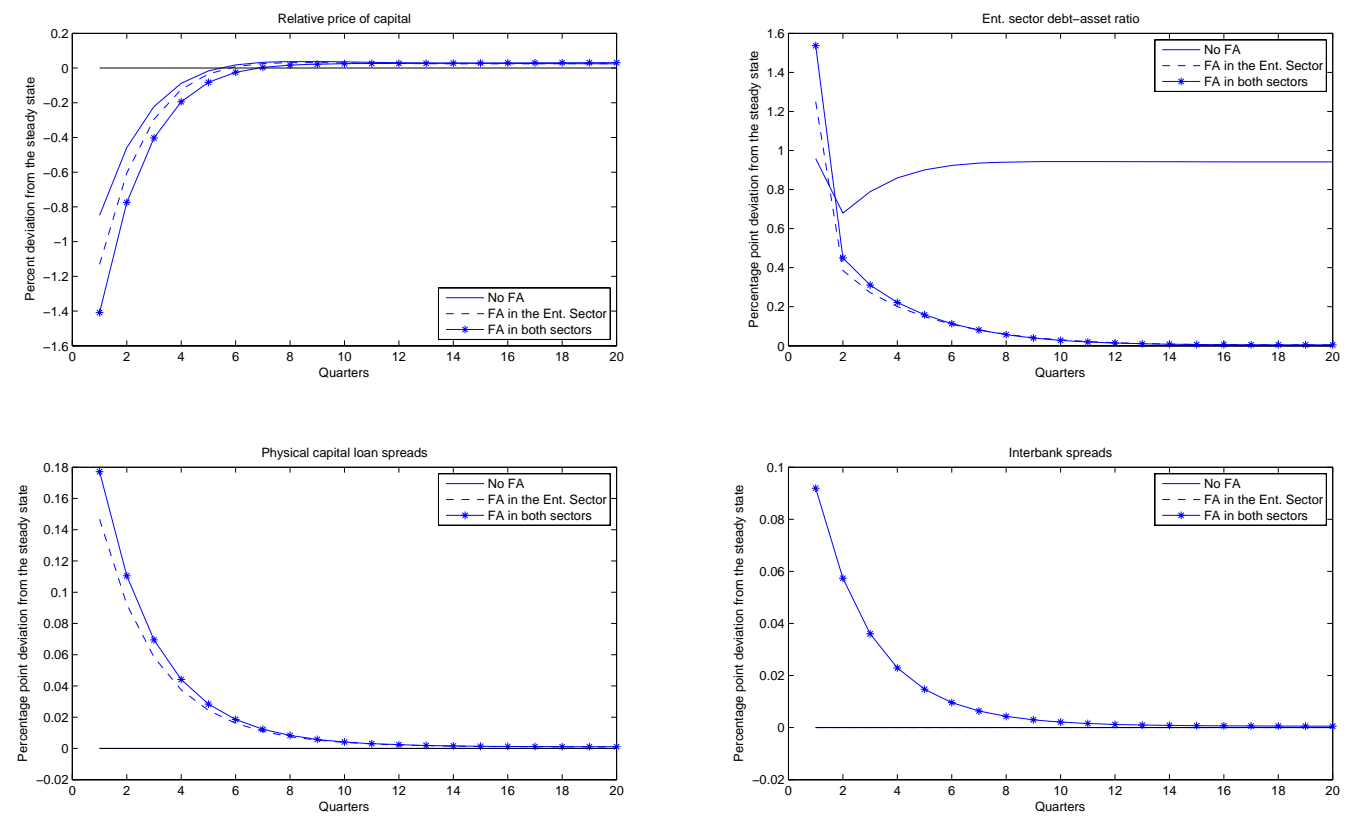
Figure 2: Responses of GDP, inflation, investment and consumption to a monetary policy shock in a closed economy.
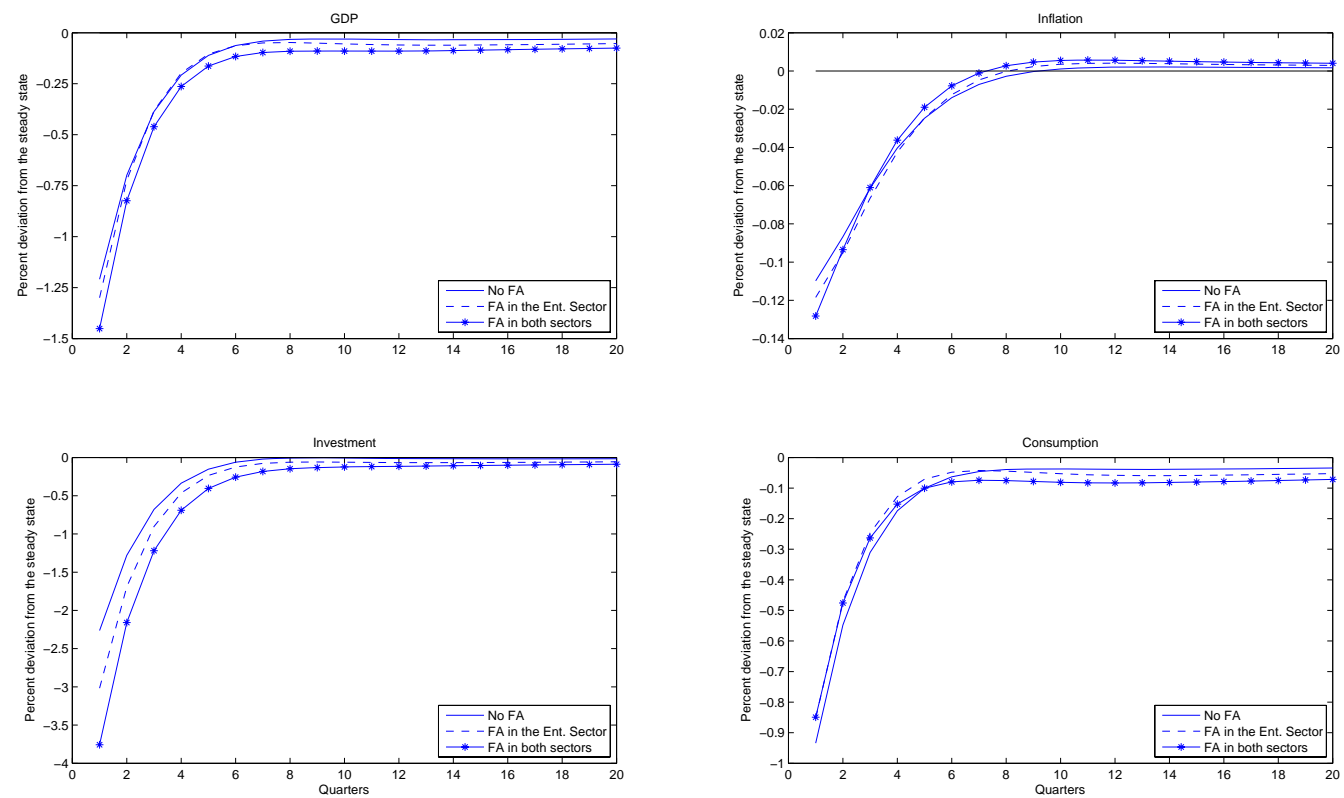

Figure 3: Responses of asset prices, debt-asset ratios, and lending spreads to a negative TFP shock in a closed economy.
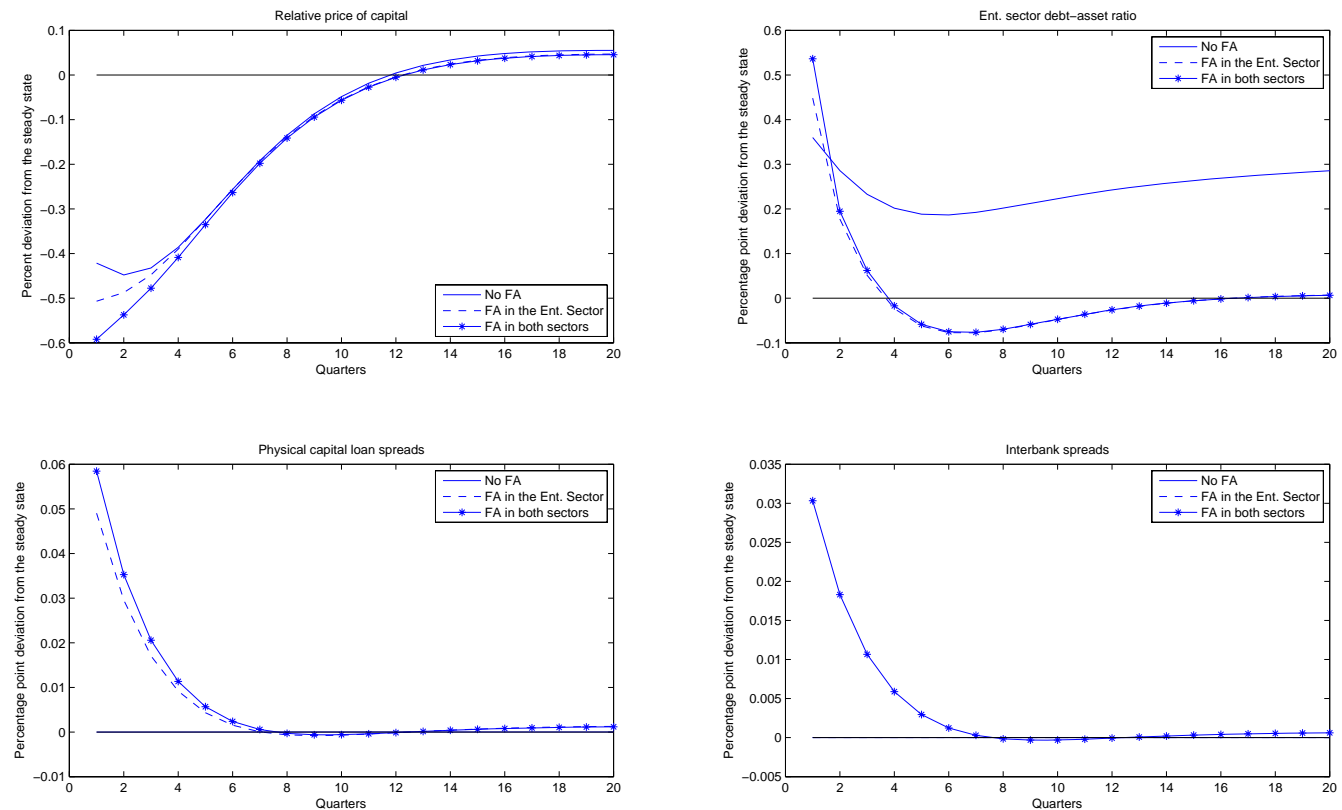
Figure 4: Responses of GDP, inflation, investment and consumption to a negative TFP shock in a closed economy.
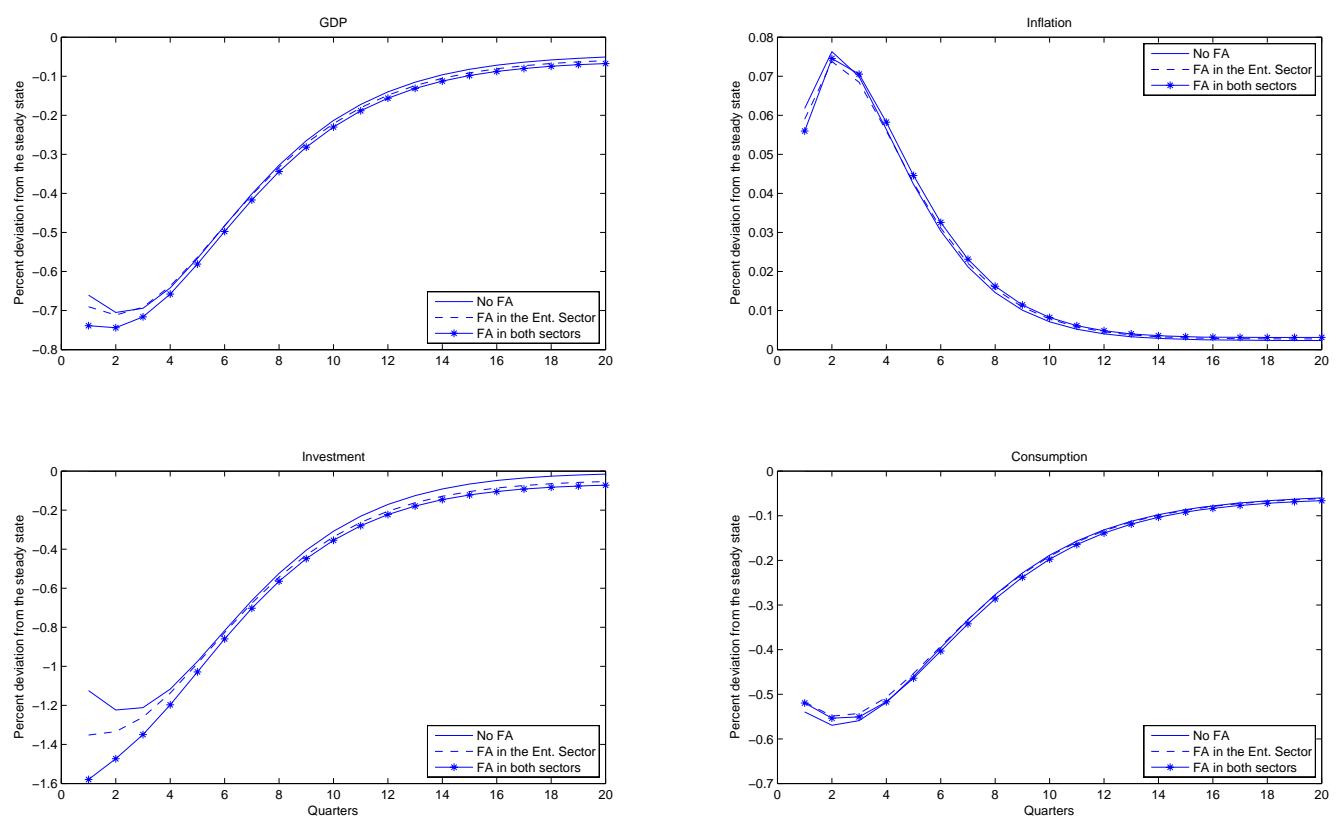

Figure 5: Responses of GDP, inflation, investment and consumption in a closed economy to a financial sector risk shock.
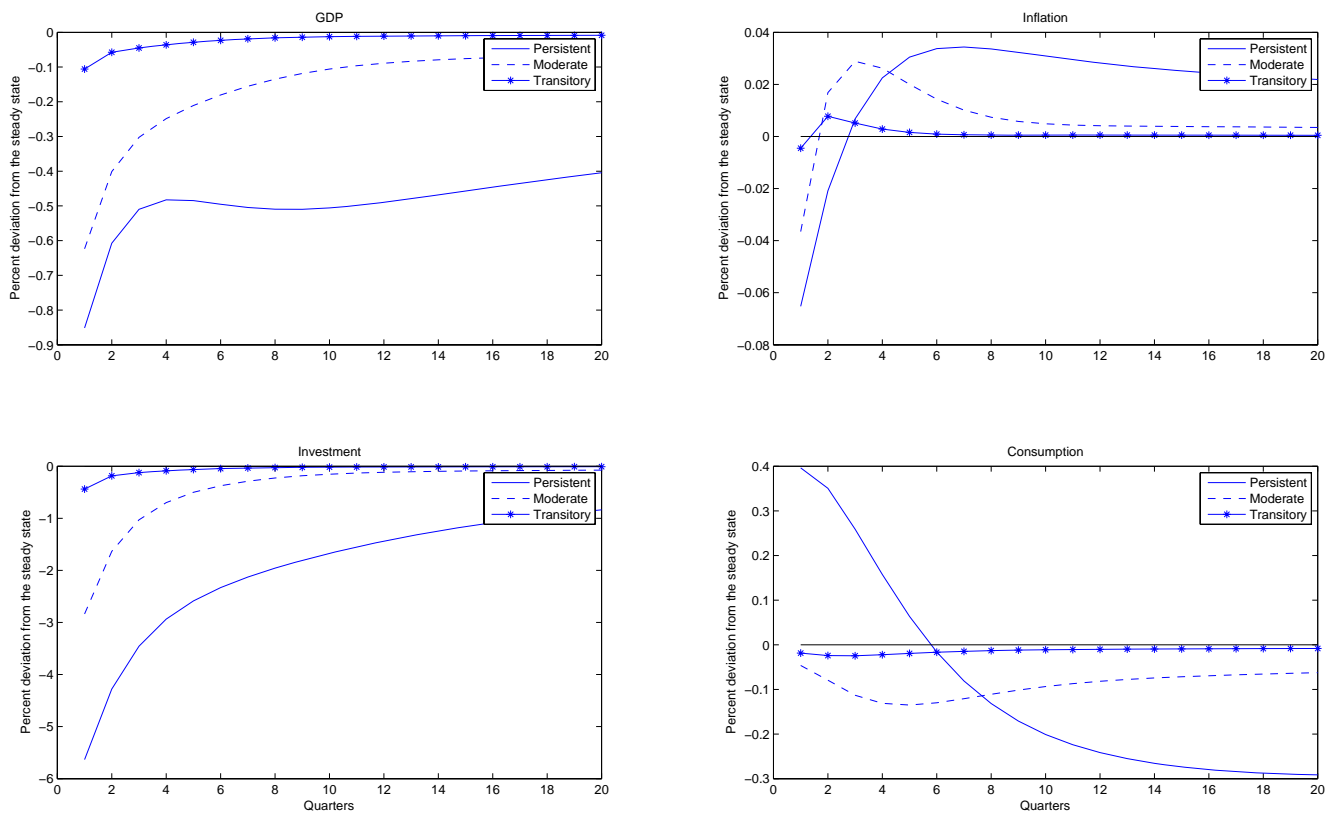
Figure 6: Responses of asset prices, financial sector uncertainty, and lending spreads to a financial sector risk shock in a closed economy.
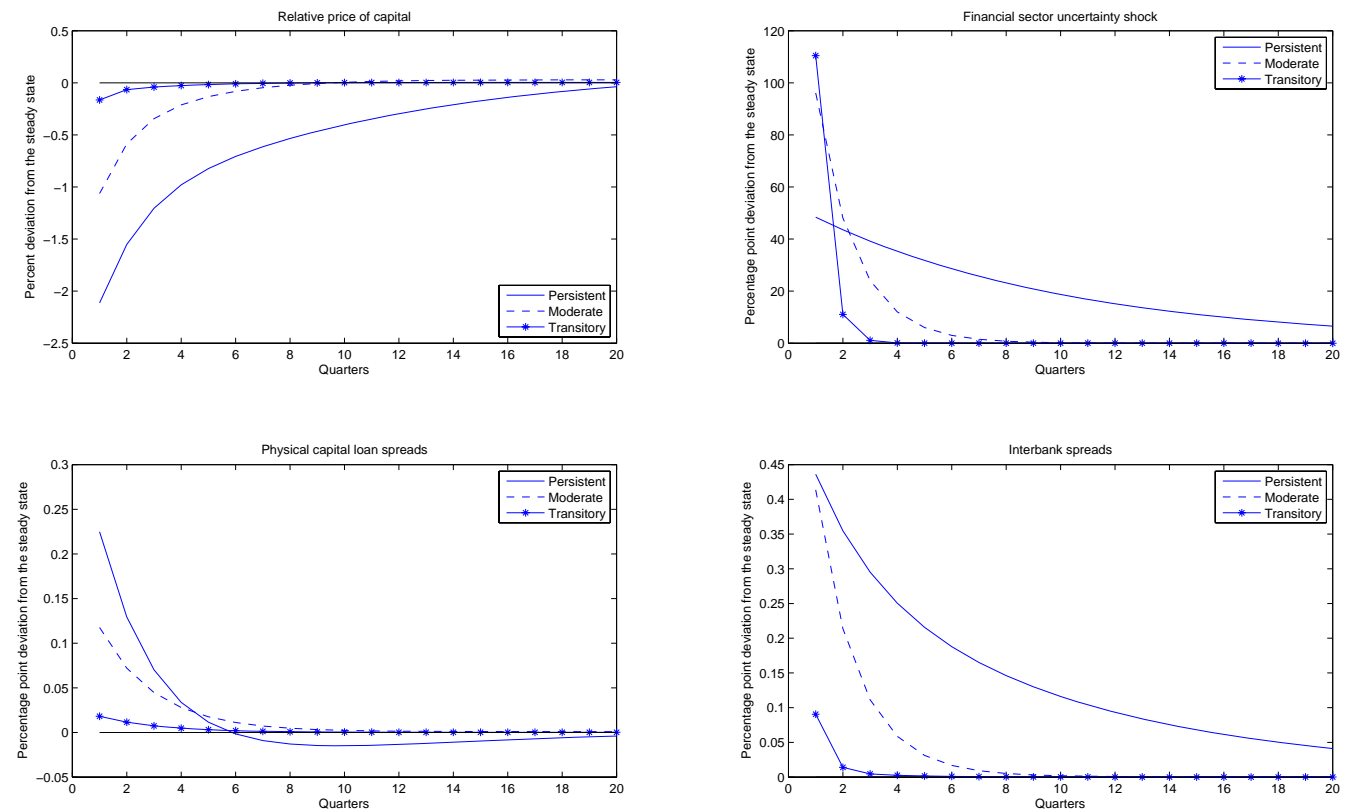